\title{
Ocean Forcing to Changes in Global Monsoon Precipitation over the Recent Half-Century
}

\author{
TIANJUN ZHOU \\ LASG, Institute of Atmospheric Physics, Chinese Academy of Sciences, Beijing, China
}

\section{RUCONG Yu}

LASG, Institute of Atmospheric Physics, Chinese Academy of Sciences, and LaSW, Chinese Academy of Meteorological Sciences, China Meteorological Administration, Beijing, China

\section{HONGMEI Li}

LASG, Institute of Atmospheric Physics, Chinese Academy of Sciences, and Graduate School of the Chinese Academy of Sciences, Beijing, China

\section{BIN WANG}

Department of Meteorology, and International Pacific Research Center, University of Hawaii at Manoa, Honolulu, Hawaii

(Manuscript received 30 May 2007, in final form 13 November 2007)

\begin{abstract}
Previous examination of changes in global monsoon precipitation over land reveals an overall weakening over the recent half-century (1950-2000). The present study suggests that this significant change in global land monsoon precipitation is deducible from the atmosphere's response to the observed SST variations. When forced by historical sea surface temperatures covering the same period, the ensemble simulation with the NCAR Community Atmosphere Model, version 2 (CAM2) model successfully reproduced the weakening tendency of global land monsoon precipitation. This decreasing tendency was mainly caused by the warming trend over the central-eastern Pacific and the western tropical Indian Ocean. At the interannual time scale, the global land monsoon precipitation is closely correlated with ENSO. The simulated interannual variation of the global land monsoon index matches well with the observation, indicating that most monsoon precipitation variations arise from the ocean forcing. There are uncertainties between the GPCP and the CMAP data in describing the evolution of global ocean monsoon precipitation. There is very little correspondence between the simulated and the observed global monsoon index over the ocean area. Uncertainties in the satellite data and model deficiencies in describing the ocean monsoon domain are partly to blame. Among the components of global monsoon systems, the Asian-Australian monsoon system has the lowest reproducibility with prescribed SST forcing due to the neglect of air-sea feedback.
\end{abstract}

\section{Introduction}

The global monsoon system is a persistent globalscale overturning of the atmosphere that varies according to the time of year (Trenberth et al. 2000). The dominant monsoon systems in the world are the AsianAustralian, African, and the American monsoons

Corresponding author address: Dr. Tianjun Zhou, LASG, Institute of Atmospheric Physics, Chinese Academy of Sciences, Beijing 100029, China.

E-mail: zhoutj@lasg.iap.ac.cn
(Webster et al. 1998). Although many studies have addressed the question of recent monsoon changes, published results have mostly focused on specific regions of the world and have used different measures of monsoon strength. For instance, the observed all-Indian precipitation over the past $131 \mathrm{yr}$ does not show global warming controlling the Indian monsoon trend (Kripalani et al. 2003). Chase et al. (2003) found that the monsoonal overturning circulations over the Australian Maritime Continent and African regions have diminished since 1950, but they detected no significant changes since 1979 in the monsoon circulation accom- 
panying the strongest reported surface warming. In recent decades, a marked summer precipitation change has been observed in eastern China. Precipitation has increased over the middle and lower reaches of the Yangtze River valley, whereas it has decreased over the middle to lower reaches of the Yellow River valley (Nitta and $\mathrm{Hu}$ 1996; $\mathrm{Hu}$ 1997; $\mathrm{Hu}$ et al. 2003). This marked precipitation change is associated with a strong tropospheric cooling trend over East Asia ( $\mathrm{Yu}$ et al. 2004). Accompanying this summer cooling, the upperlevel westerly jet stream over East Asia shifts southward and the East Asian summer monsoon weakens, which results in the tendency toward increased droughts in northern China and excessive rainfall along the Yangtze River Valley (Yu and Zhou 2007). Xin et al. (2006) revealed that during 1958-2000 South China has undergone a significant decrease in late spring precipitation since the late 1970s. The 1950-99 time histories of northern and southern Africa rainfall during their respective wet seasons are well described by linear downward trends (Hoerling et al. 2006). A trend toward increased aridity since 1950 has emerged over southern Africa and a $20 \%$ reduction in the climatological February-March-April rainfall has been observed there since 1950 , compared with a $35 \%$ reduction over the same period for the Sahel (Hulme 1996).

Considering the coordination among regional monsoons brought about by the annual cycle of the solar heating and the connections in the global divergent circulation necessitated by mass conservation (Trenberth et al. 2006), it is desirable to examine the monsoon variability from a global perspective. Previous analyses of interannual and interdecadal variations suggest that the global monsoon system does not vary coherently (e.g., see Webster et al. 1998). A recent examination of the changes in the global monsoon rainfall over land by using four sets of rain gauge precipitation datasets compiled for the period of 1948-2003 by climate diagnostic groups around the world found an overall weakening of the global land monsoon precipitation in the last $56 \mathrm{yr}$, primarily due to the weakening of the summer monsoon rainfall in the Northern Hemisphere (Wang and Ding 2006). This observational metric for quantifying the changes of global monsoon precipitation has provided a rigorous test for climate models.

Hoerling et al. (2006) found that the spatial patterns, time history, and seasonality of African rainfall trends since 1950 are deducible from the atmosphere's response to the known variations of global sea surface temperatures (SSTs). Drying over the Sahel during boreal summer is shown to be a response to warming in the South Atlantic relative to North Atlantic SST; southern African drying during austral summer is shown to be a response to Indian Ocean warming. However, the role of ocean forcing in producing the changes in the global monsoon precipitation as a whole has not been investigated. The present study aims to explore the causes for the decreasing trend of global land monsoon rainfall by addressing the following questions: Have significant changes of global land monsoon rainfall been detected that are likely to be deducible from the atmosphere's response to the observed SST variations? Are the secular drying trends over specific monsoon regions attributable to common oceanic influences? Which oceanic SST variations have been the most relevant to the long-term trend and interannual variability of the global land monsoon rainfall, respectively? We employ an Atmospheric Model Intercomparison Project (AMIP) model approach to gain insight on these questions and to quantify the robustness of oceanic impacts on global land monsoon rainfall. In particular, we examine the global land monsoon rainfall sensitivity to the observed variations in global SSTs during the last half of the twentieth century using ensemble simulations of an atmospheric general circulation model (AGCM). Our results suggest that the decreasing tendency of the global land monsoon precipitation during the last half-century was mainly caused by the warming trend over the central-eastern Pacific and the western tropical Indian Ocean. At the interannual time scale, the global land monsoon precipitation is closely correlated with ENSO. If global SSTs are known and prescribed to an AGCM, both the secular tendency and the interannual variation of the global land monsoon precipitation are highly reproducible. Over the Asian-Australian monsoon domain, however, the reproducibility is lower due to the neglect of air-sea feedback.

This paper is organized as follows. The model, its experimental design, the observational data, and the analyses method are described in section 2 . Results are presented in section 3 , including an appraisal of the model capacity to simulate the climatological global monsoon rain domain according to the annual precipitation range, and a diagnosis of the AGCM-simulated rainfall trends over the global land monsoon domain and a comparison with 52-yr rainfall trends occurring in combined rain gauge precipitation data. Section 3 also explores the role of specific SST forcing using the global SST history since 1950, and we focus on the role of ocean changes at a long-term trend and the interannual time scale. The extent to which rainfall changes over the global ocean monsoon domain are deducible from the atmosphere's response to ocean forcing is also examined in section 3. Concluding remarks including a discussion are given in section 4 . 


\section{Model data and analysis method}

In this study, we examine the SST-induced changes in global monsoon precipitation over a 52-yr period (1949-2000) based on a set of atmospheric climate model ensembles forced by observed historical SST data. The model datasets come from the National Center for Atmospheric Research (NCAR) Community Atmosphere Model, version 2.0.1 (CAM2.0.1) global SST-forced 15-member ensemble simulation. Fifteen simulation runs were carried out using CAM2.0.1 (hereafter CAM2) and observed SSTs from January 1949 to October 2001 by the NCAR climate variability working group (more information is available online at http://www.ccsm.ucar.edu/working_groups/Variability/ index.html). The model is a global primitive equation spectral model with T42 triangular truncation and 26 vertical levels. (Details of the model are described online at the NCAR Web site: http://www.ccsm.ucar.edu/ models/ccsm2.0.1/cam/camUsersGuide/.) Ensemble methods are employed in which 15 integrations are begun from different atmospheric initial conditions, but subjected to identically specified sea surface temperature conditions. The sea surface temperature boundary dataset for the CAM2 model was constructed by Hurrell et al. (2008). It is a merged product based on the monthly mean Hadley Centre SST dataset version 1 (HadISST1) and version 2 of the National Oceanic and Atmospheric Administration (NOAA) weekly optimum interpolation (OI.v2) SST analysis. This dataset is also used to construct the Niño-3.4 index time series in the following analysis. The Niño-3.4 index is calculated as the regional average of SST anomalies over the region of $5^{\circ} \mathrm{N}-5^{\circ} \mathrm{S}, 170^{\circ}-120^{\circ} \mathrm{W}$. Output of the ensemble simulation has been used in many studies (e.g., the forcing of El Niño to the southern annular mode; Zhou and $\mathrm{Yu}$ 2004). Note the ensemble simulation driven by the history of global observed SSTs, namely the AMIPtype run, is termed as "forcing run." In addition to the forcing run, we have also performed a 62 -yr control run forced by climatological SST (hereafter the control run). The first 10 -yr period is discarded as a spinup process and the output of the remaining 52-yr simulation is used in the analysis.

Three sets of monthly rain gauge precipitation data for global land surfaces on different degree latitudelongitude grids compiled by climate diagnostic groups around the world were used: 1) the dataset compiled by Delaware University (Delaware) for the period of 1950-99 (Willmott and Matsuura 2001), 2) the dataset constructed by the Climatic Research Unit (CRU) for the period of 1900-98 (Hulme et al. 1998; New et al. 1999), and 3) the Precipitation Recconstruction data over Land (PREC/L) compiled for the period of 19482006 by the Climate Prediction Center (CPC) at the National Centers for Environmental Prediction (NCEP; Chen et al. 2002).

Following Wang and Ding (2006), to reduce the uncertainties arising from differences in data sources and interpolation algorithms, an ensemble (arithmetic) mean of the three datasets was calculated over the global land areas for the period of 1949-2001. To facilitate analysis, the original data were interpolated onto a $1.0^{\circ}$ longitude by $1.0^{\circ}$ latitude grid by using a bilinear interpolation technique. In addition, Global Precipitation Climatology Project (GPCP) data for the period of 1979-2003 (Huffman et al. 1997; Adler et al. 2003), and the CPC Merged Analysis of Precipitation (CMAP) data for the same period (Xie and Arkin 1996) were used to investigate global monsoon trends over ocean areas during the last $25 \mathrm{yr}$. In addition, the satellite precipitation observations from the Special Sensor Microwave Imager (SSM/I), which extends from 1987 to the present, are also used (Wentz and Spencer 1998).

The monsoon climate is characterized by a rainy summer and a dry winter. Precipitation is the most fundamental variable for determining the monsoon climate. As in Wang and Ding (2006), the local summerminus-winter precipitation, defined as the annual range (AR), is used in the analyses. Here, summer means June-August (JJA) in the Northern Hemisphere (NH) and December-February (DJF) in the Southern Hemisphere (SH). The global monsoon precipitation domain is defined by the region in which the AR exceeds 180 $\mathrm{mm}$ and the local summer monsoon precipitation exceeds 35\% of annual rainfall. Wang and Ding (2006) proved that this simple definition is in an excellent agreement with the monsoon domains that have been previously defined based upon more complex multiple criteria (Wang and Lin 2002).

Three methods were used to measure the monsoon precipitation intensity. The first method measured the global mean intensity. Since the monsoon annual range is dominated by local summer precipitation, the NHaveraged JJA monsoon precipitation (i.e., the precipitation falling in the $\mathrm{NH}$ land monsoon domain) and the $\mathrm{SH}$-averaged DJF monsoon precipitation were used to measure the strength of the $\mathrm{NH}$ and $\mathrm{SH}$ summer monsoon rainfalls, denoted by NHMI and SHMI, respectively. The sum of NHMI and SHMI, which was termed the global monsoon index (GMI), was used to quantify the global mean monsoon strength. The second approach was designed to reveal the coherent pattern of the change in global monsoon precipitation intensity. Since the AR varies from year to year, each year's AR was defined as the local summer precipitation minus 
(a)Annual range

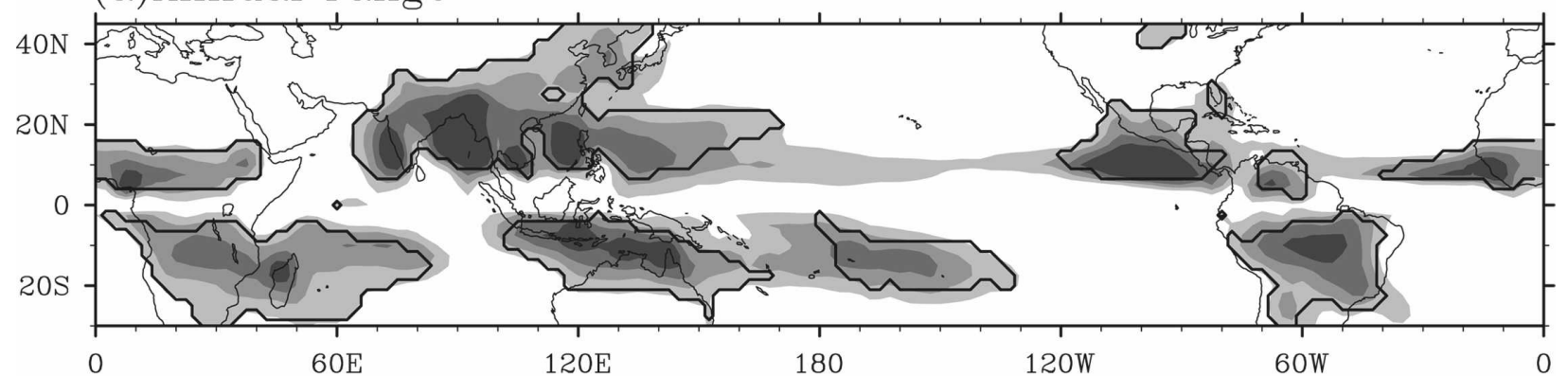

(b)Annual mean precipitation rate
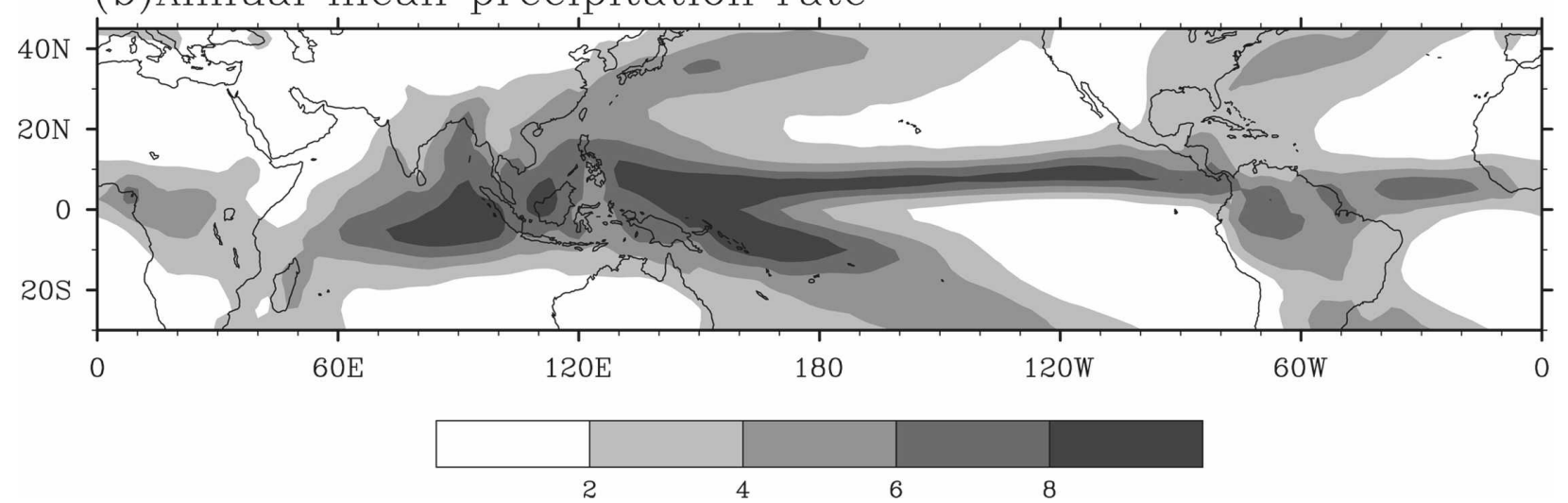

FIG. 1. (a) The climatological mean for the annual range of precipitation, defined by the local summer mean precipitation rate (JJA in the $\mathrm{NH}$ and $\mathrm{DJF}$ in the $\mathrm{SH}$ ) minus the local winter mean precipitation rate. The bold lines delineate the global monsoon domain. (b) The long-term mean for total annual precipitation. The data used are a blended CMAP data (1979-2003). Units are mm day ${ }^{-1}$.

the preceding local winter precipitation. The leading empirical orthogonal function (EOF) pattern of yearly AR was used to describe the primary spatial variability of the AR, while the corresponding time coefficient was used to describe temporal behavior; this was termed the annual range index (ARI). The third method tested the statistical significance of the AR trend for each grid point within the monsoon domain. Both the trend-tonoise ratio and Mann-Kendall rank statistics (Sneyers 1990) were used to test the significance of linear trends.

\section{Results}

\section{a. Evaluation on the simulated monsoon domain}

Figure 1 shows the global distribution of AR of the climatological precipitation and the long-term mean for total annual precipitation based on CMAP data (Xie and Arkin 1996). The spatial patterns of the annual range of precipitation and the annual mean precipitation rate all closely resemble those of GPCP data (Wang and Ding 2006), that is, the major monsoon rainy regions tend to reside on each side of the equatorial perennial rainfall regions and the global monsoon rainfall differs from that of the global mean precipitation, which tends to be maximized at the equator and is generally more equatorially symmetric.

Figure 2 shows the spatial distributions of AR of the climatological precipitation and the annual mean precipitation rate simulated by the CAM 2 model. The CAM2 model has reasonable performances in simulating the observed major monsoon rainy regions, which include the southern African monsoon region, the South and East Asian monsoon region, the Australian monsoon region, and the southern American monsoon region. The simulated annual range of precipitation over the northern African monsoon regions is weaker than the observation. The Central American and the western Pacific monsoon rainfall are weakly simulated in the model. The observed monsoon rainy regions over the central tropical South Pacific and the tropical eastern Pacific are also weak in the simulation.

In addition, the observed South Pacific convergence zone appears as a spurious intertropical convergence zone (ITCZ) precipitation band south of the equator in the central and eastern Pacific in the CAM2 simulation. This so-called double ITCZ problem often exists in the atmospheric GCM and is amplified in the fully coupled 


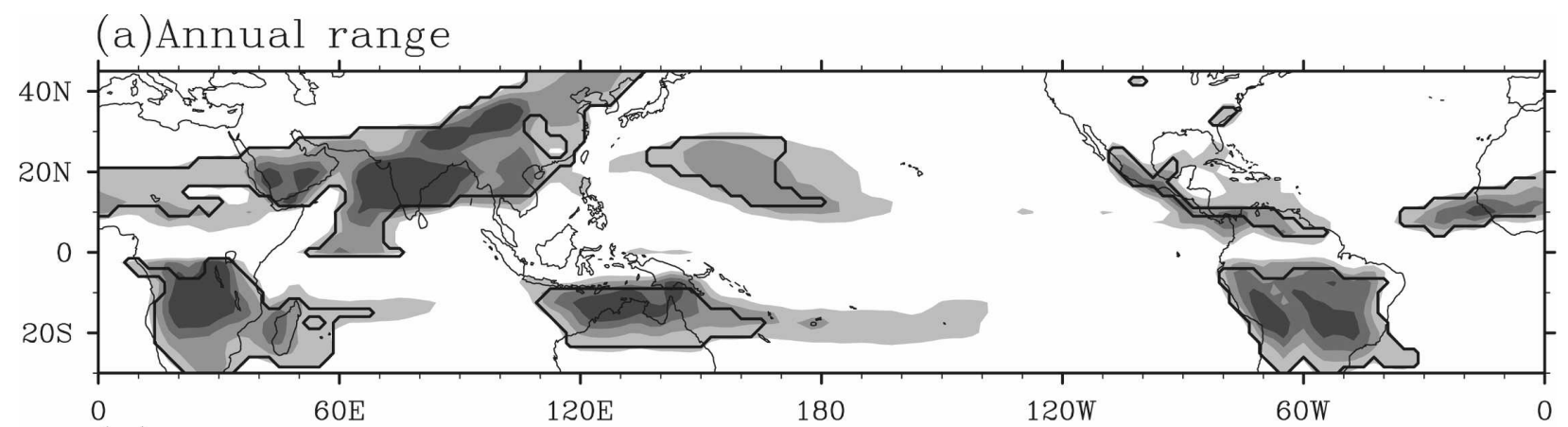

(b)Annual mean precipitation rate
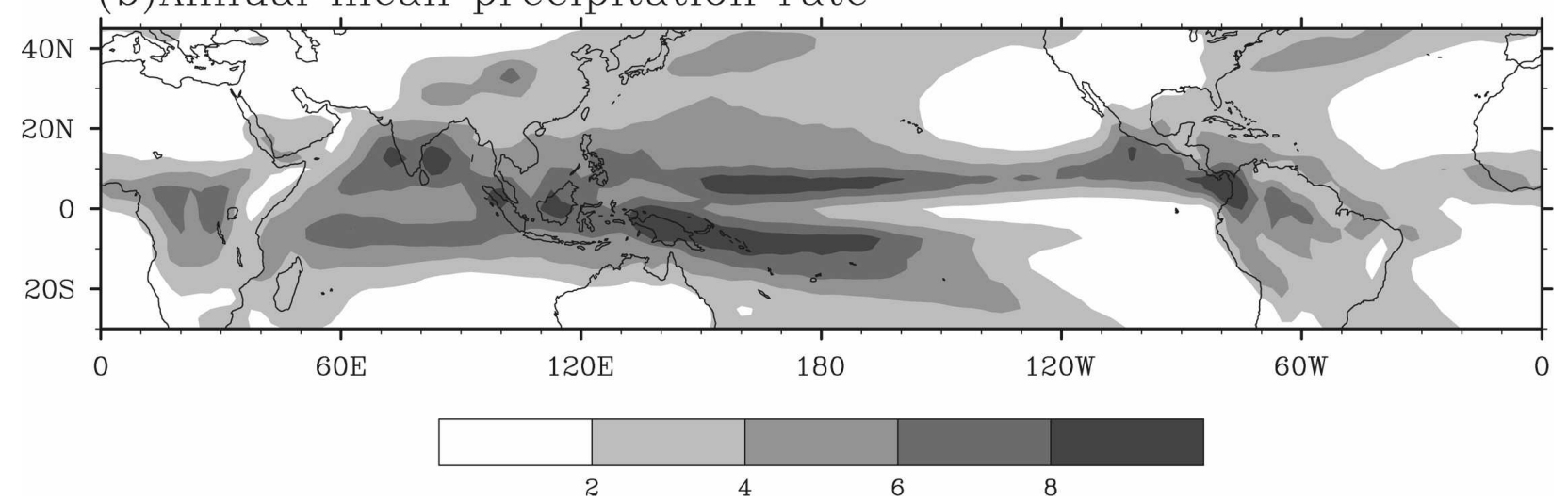

FIG. 2. As in Fig. 1, but for the ensemble mean of 15 realizations of CAM2 forced by observational SST.

model (Zhang and Wang 2006). The deficiency of the CAM2 model in producing the observed monsoon rainy regions over the central tropical South Pacific is partly ascribed to the ill-simulated double ITCZ.

\section{b. Changes in precipitation intensity over the land monsoon domain}

Figure 3 shows the time series of the NHMI, SHMI, and the GMI derived from the ensemble mean of 15 realizations of the CAM2 simulation, along with the ensemble mean of three observational datasets. All indices are shown in terms of anomalies relative to climate mean values. The climate mean values of the NHMI, SHMI and GMI have nearly the same intensity of $6.49 \mathrm{~mm} \mathrm{day}^{-1}$. The corresponding values of the simulation are 5.95, 6.88, and $6.41 \mathrm{~mm} \mathrm{day}^{-1}$, respectively. The climatological mean monsoon precipitation is weaker (stronger) than the observation in the Northern (Southern) Hemisphere.

It is obvious that the variability of the observations is larger than that of the simulations. Note that the average uses more grids $\left(1^{\circ} \times 1^{\circ}\right.$ resolution $)$ in observation than in the simulation $\left(\mathrm{T} 42\right.$, about $2.8^{\circ} \times 2.8^{\circ}$ resolution). Besides the difference in physics, another possi- bility is the difference in the ensemble means: the observation is a 3 -member average but the simulation is a 15-member average.

The observational time series indicates a decreasing trend in the NHMI across the entire $50 \mathrm{yr}$, and particularly before 1980 . This decreasing trend is also apparent in the global monsoon index. The Southern Hemisphere monsoon index, however, shows no significant trend. The observational decreasing trend in the NHMI index can be found in the CAM2 simulation. It is however slightly weaker than the observation. The simulated trend is $-0.36 \mathrm{~mm}$ day $^{-1}(50 \mathrm{yr})^{-1}$, while the observational value is $-0.59 \mathrm{~mm} \mathrm{day}^{-1}(50 \mathrm{yr})^{-1}$. The simulated decreasing trend of GMI is comparable to the observation, with a trend of $-0.21 \mathrm{~mm}$ day $^{-1}$ $(50 \mathrm{yr})^{-1}$ versus the observed value of $-0.34 \mathrm{~mm} \mathrm{day}^{-1}$ $(50 \mathrm{yr})^{-1}$. The simulated SHMI index shows no apparent trend $\left(-0.05 \mathrm{~mm}\right.$ day $^{-1}(50 \mathrm{yr})^{-1}$, which is consistent with the observation $\left[-0.09 \mathrm{~mm}^{-1 a y}{ }^{-1}(50 \mathrm{yr})^{-1}\right]$. This result shows that the decreasing tendency of the global land monsoon index in the past decades has oceanic origins.

In addition to the decreasing trend, the NHMI also shows robust interannual variability (Fig. 3a). Similar variations are seen in the SHMI and GMI time series (Figs. 3b,c). The correlation coefficients between the 
(a) $\mathrm{NH}$ averaged JJA rainfall( $\mathrm{mm} /$ day)

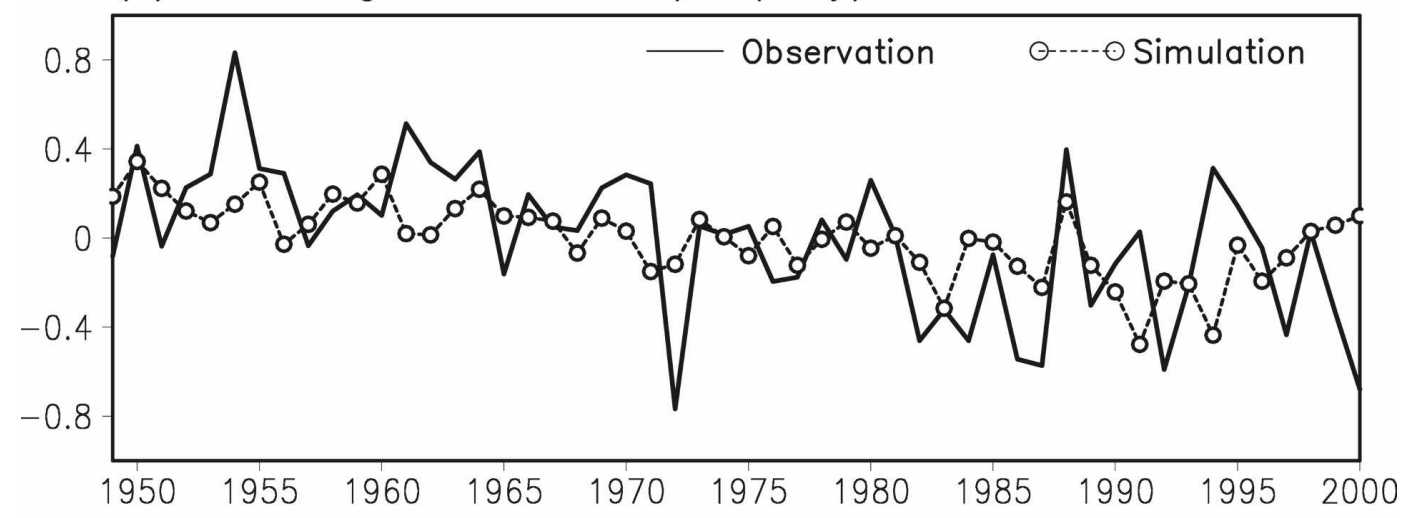

(b) $\mathrm{SH}$ averaged DJF rainfall( $\mathrm{mm} /$ day)

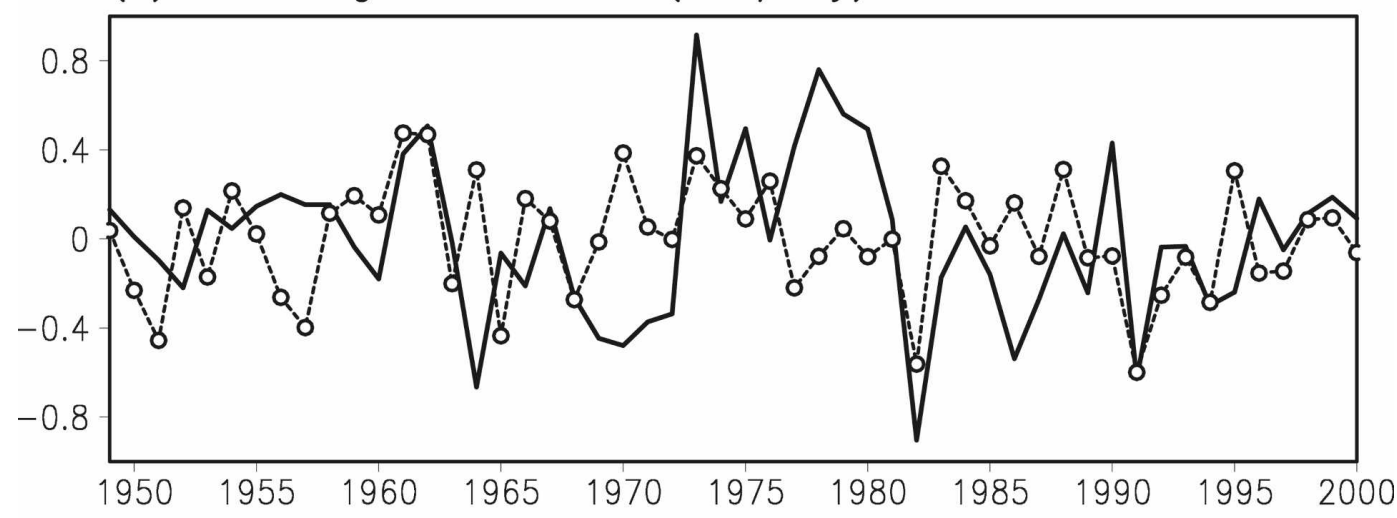

(c) $\mathrm{NH}+\mathrm{SH}$ averaged local summer rainfall( $\mathrm{mm} /$ day $)$

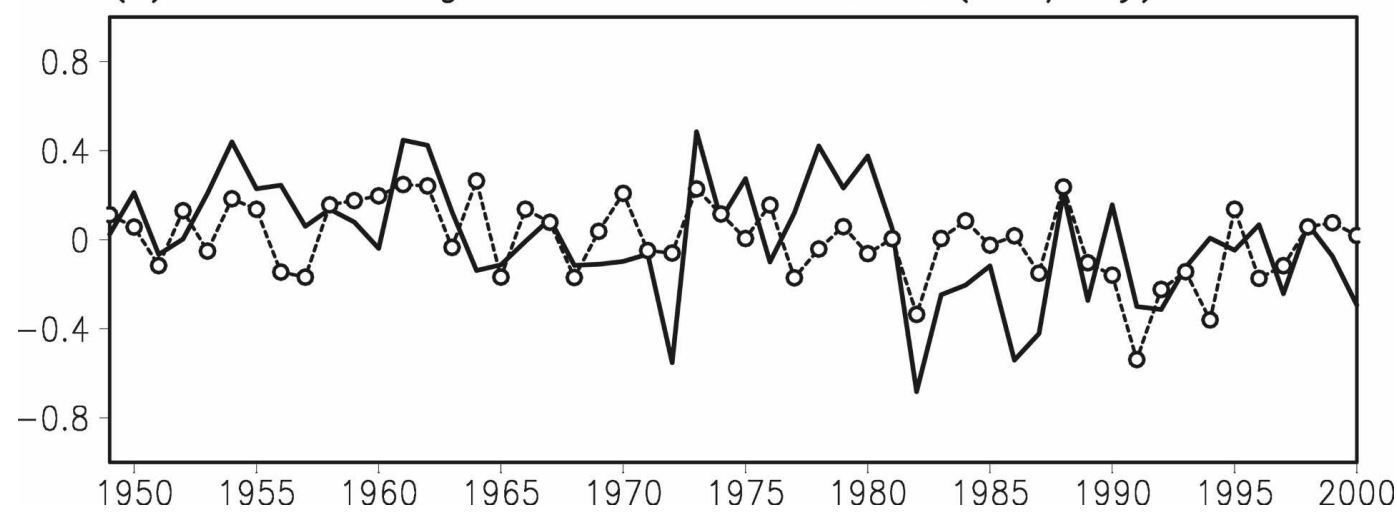

FIG. 3. Time series of (a) the NH-averaged JJA precipitation, (b) the SH-averaged DJF precipitation, and (c) the GMI, or the sum of (a) and (b). The data used are the ensemble mean of 15 realizations of the CAM2 model forced by observational SST and three precipitation datasets (described in the text) for the period of 1949-2001. The curve marked as "observation" is the mean of the three precipitation datasets. The time series are given as anomalies relative to the climate mean. Units are $\mathrm{mm} \mathrm{day}^{-1}$.

simulation and the observation are 0.38 for the NHMI, 0.22 for the SHMI, and 0.42 for the GMI. After linear detrending, the correlation coefficients are 0.06, 0.22, and 0.33 , respectively. The correlation coefficient for the GMI is still statistically significantly at the 5\% level, indicating that most of the monsoon variability arises from the oceanic forcing. Taking an average of the NHMI and SHMI shows the prominence of the lowfrequency variability since the high-frequency variability is smoothed away. 
(a) $\mathrm{NH}$ averaged JJA rainfall( $\mathrm{mm} /$ day)

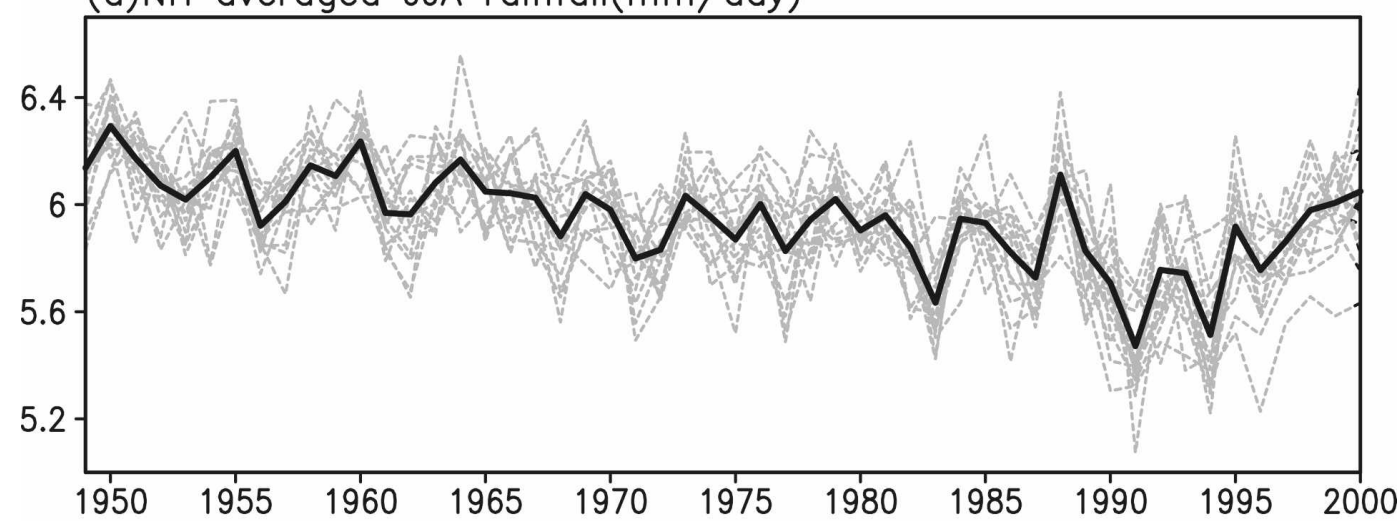

\section{(b) SH averaged DJF rainfall( $\mathrm{mm} /$ day)}

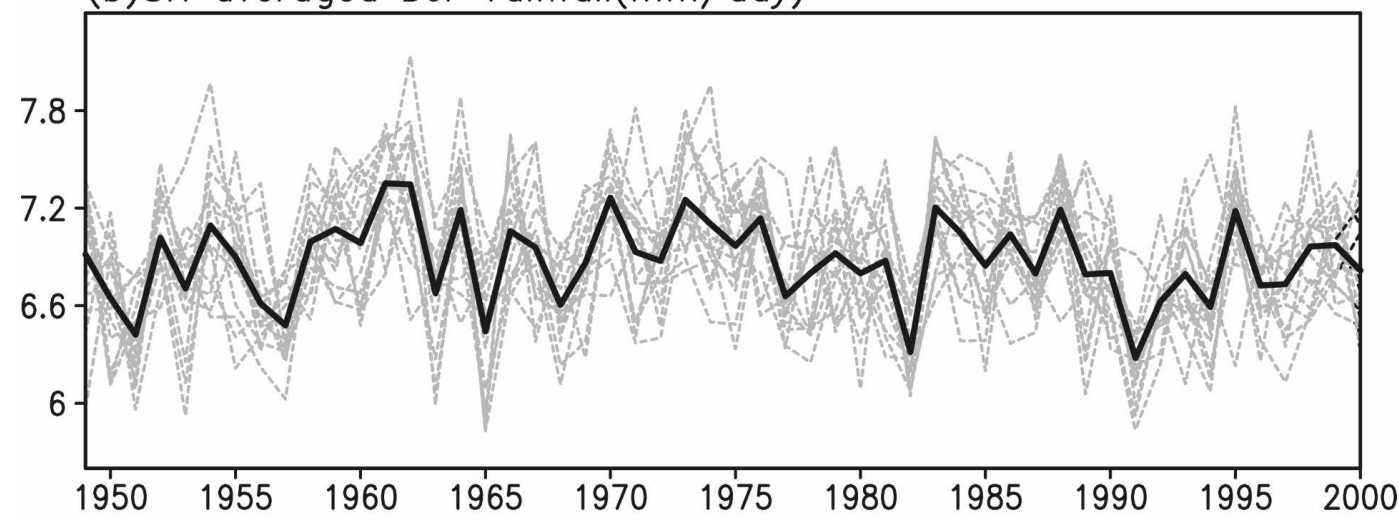

(c) $\mathrm{NH}+\mathrm{SH}$ averaged local summer rainfall( $\mathrm{mm} /$ day)

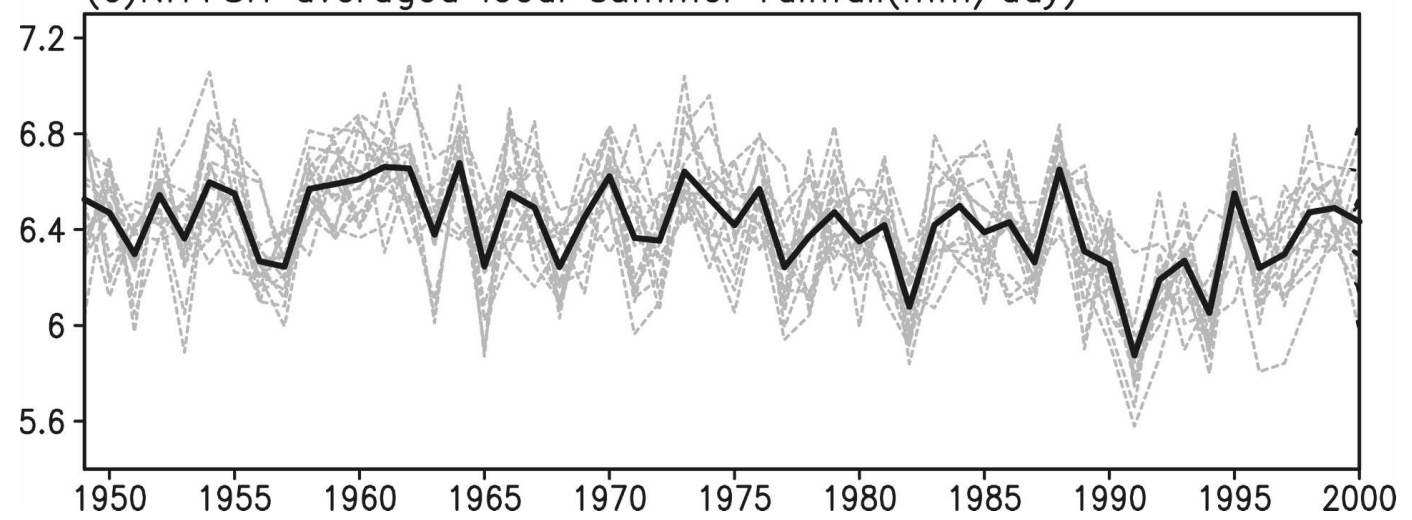

FIG. 4. As in Fig. 3, but for each single realization of the ensemble simulation. Each thin gray line corresponds to one realization. The thick black line is for the ensemble average.

One typical feature of Fig. 3 is that the simulated amplitudes of the rainfall indices are in general weaker than the observation. This difference is not unexpected as using ensembles improves the correlation as random variations are reduced during the averaging. Working with ensembles increases the correlation, but decreases the amplitude (Zhou and Yu 2006). This is further manifested in Fig. 4, which shows the time series of the NHMI, SHMI, and the GMI derived from each individual realization of the CAM2 simulation. Spreads are seen among the simulated time series for different realizations, indicating the impact of internal dynamics of the atmospheric motion. To quantitatively reveal the contributions of external SST forcing and internal noise 
to the simulated monsoon index variation, the widely used technique of analysis of variance is employed ( $\mathrm{Li}$ 1999; Zhou and Yu 2006). Analysis on the NHMI index shows that the internal atmospheric dynamics accounts for $41 \%$ and the external SST forcing accounts for $59 \%$ of the total variance, with a signal-to-noise ratio of 1.19. For the SHMI time series, the corresponding statistics are $60 \%$ and $40 \%$, respectively, with a signal-to-noise ratio of 0.81 . The forced signal is hence much larger than the internal noise in the NHMI, while a reverse condition is found in the SHMI. This is the reason why the NHMI has a higher reproducibility than the SHMI, as shown by the correlation coefficient between the observation and the simulation. For the GMI time series, the internal atmospheric dynamics accounts for $11 \%$ and the external SST forcing accounts for $89 \%$ of the total variance, with a signal-to-noise ratio of 2.8 . Hence it is highly reproducible.

Figure 5a shows the coherent spatial pattern of the leading EOF mode of the global land monsoon precipitation AR, which is obtained by analysis of the correlation matrix based on the three-member ensemble mean precipitation dataset. Figure $5 b$ is the same as Fig. 5a except for the model result, which is based on the 15-member ensemble mean CAM2 simulation. The corresponding observational ARI shows a decreasing tendency for the entire period examined (Fig. 5c). This is consistent with the result of Wang and Ding (2006), which used four-member ensemble mean precipitation datasets. The variance explained by the leading mode is comparable to that of Wang and Ding (2006). It is interesting to note that the model results match, nearly identically, the observation in this decreasing tendency, with a simulated trend of $-1.68 \mathrm{~mm} \mathrm{day}^{-1}(50 \mathrm{yr})^{-1}$ versus the observed trend of $-2.19 \mathrm{~mm} \mathrm{day}^{-1}(50 \mathrm{yr})^{-1}$ (Fig. 5c). The time series of the leading principle component reasonably matches that of the observation, with a correlation coefficient of 0.60 between the observed and simulated PCs for the 1950-2000 periods (Fig. 5c). After linear detrending, the correlation coefficient reduces to 0.46 , which is still statistically significant at the 5\% level. Based on Mann-Kendall rank statistics (Sneyers 1990), the decreasing trend of the simulated ARI is significantly different from zero at the 99\% confidence level. The same conclusion applies to the observational data.

The decreasing trend of ARI derived from the ensemble simulation has similar levels of statistical significance as the observed counterparts. However, the fractional variance of the leading EOF mode derived from the ensemble simulation is considerably higher than the observed counterpart, with $20.9 \%$ versus $10.7 \%$. The result indicates that the ensemble mean produces the distinguished leading mode and its time evolution well, but it tends to exaggerate the relevant fractional variance. This difference might be due to the fact that only SST forcing was prescribed in the model simulation, while in nature, the effects of many other forcing factors such as aerosol, change in solar activity, etc., may affected SST, and thus have an implicit impact.

The majority of land monsoon regions in observation show a coherent decreasing trend, with the largest amplitude over the North Africa (Fig. 5a). The trends over South Africa, South and East Asia, and South America are also robust. The spatial pattern of the leading EOF mode over the South America monsoon region appears as zonal positive anomalies. The largest discrepancy between the observation and the simulation is seen in the Asian monsoon domain. The observed positive polarities over the South Asian monsoon regions are absent in the simulation (Fig. 5b), indicating a poor reproducibility of monsoon rainfall over this domain. The recent weakening trend of monsoon rainfall over northern China is only weakly reproduced.

Observational analyses found that the decreasing trend of global monsoon rainfall intensity has been leveling off since 1980, even though the global mean temperature has experienced the most rapid increase during this period (Chase et al. 2003; Yu et al. 2004; Wang and Ding 2006). As shown in Fig. 5c, the declining trend of the ARI in the simulation also leveled off since 1980, suggesting an oceanic driving mechanism might be at work on the leveling off of the monsoon index.

The ARI indices for different realizations are shown in Fig. 5d. The ARI index was calculated by projecting the anomalies of AR for single realization onto the EOF1 pattern shown in Fig. 5b. Analysis of variance following $\mathrm{Li}$ (1999) shows that the external SST forcing accounts for $73 \%$ of the total variance, while the internal dynamics of the atmospheric motion accounts for only $27 \%$. The forced signal is larger than the internal noise, with a signal-to-noise ratio of 1.63 . Working with ensembles clearly improves the simulation, although the noise is more robust in mid- and high latitudes than in low (tropical and subtropical) latitudes (Zhou and Yu 2004).

The calculation of the signal-to-noise ratio could be related to the number of ensemble members of the CAM2 simulation. The change of the signal-to-noise ratio as a function of sample size is given in Fig. 5e. When the sample size is less than 7, the signal-to-noise ratio is increased with the sample size. Starting from a sample size of 7 , if more members of simulation are considered, the noise is also increased, and thus the signal-to-noise ratio is decreased. Nevertheless, the am- 
(a)First EOF of observed annual range (10.7\%)
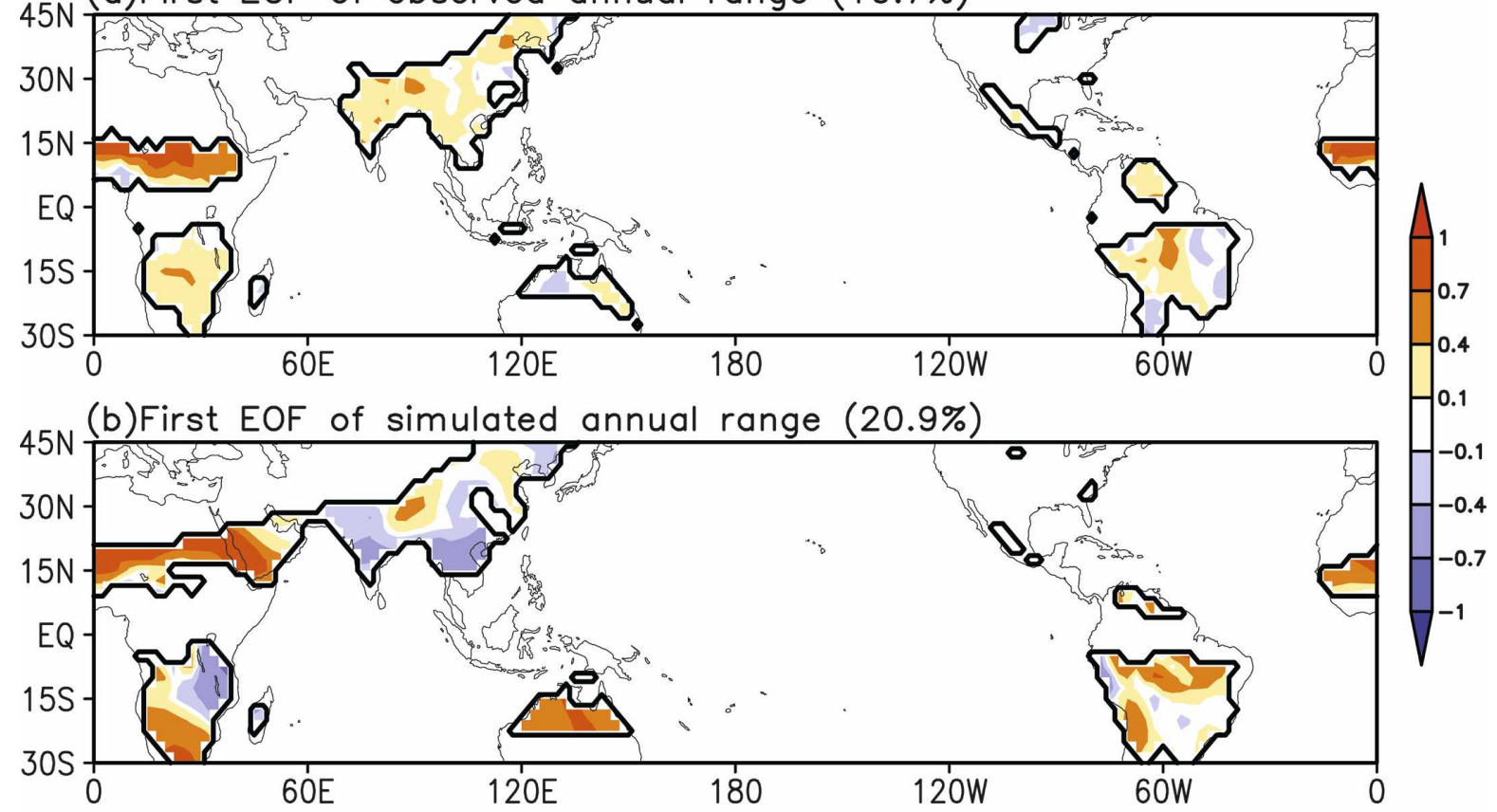

(c)Leading principle component

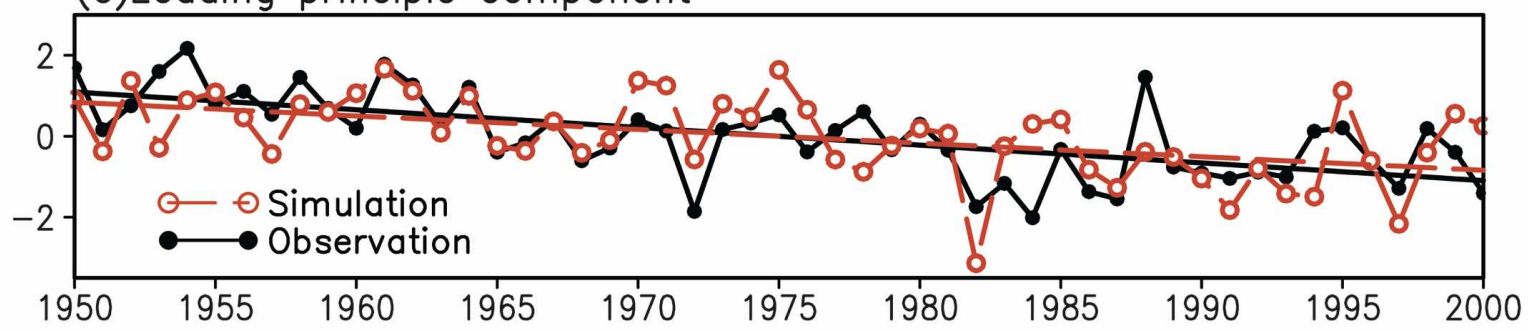

(d)Leading principle component of each realization

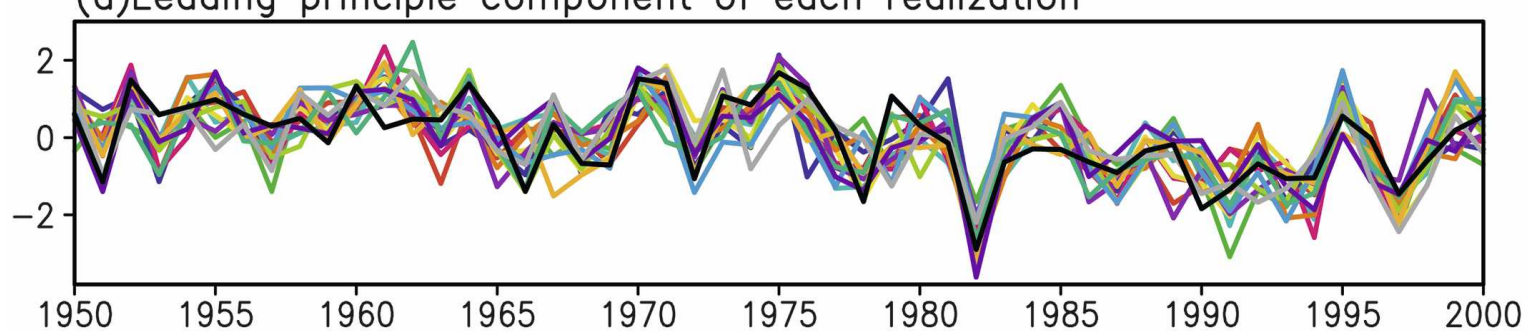

(e)Signal-noise ratio

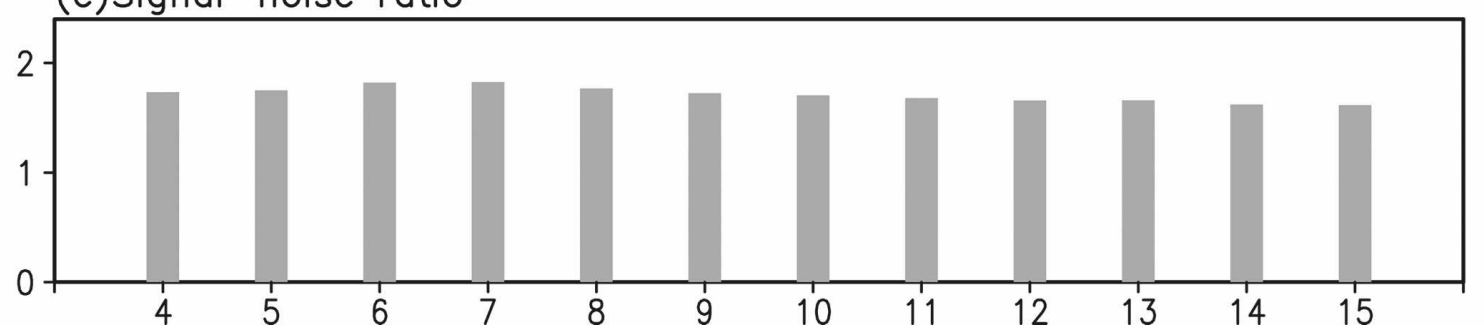

FIG. 5. The spatial pattern of the leading EOF mode of the normalized annual range anomalies over the global continental monsoon regions in (a) the observation and (b) the CAM2 simulation; (c) the corresponding principle component or ARI. (d) The ARI for each of 15 realizations of the CAM2 ensemble simulation. (e) Changes of the signal-to-noise ratio for the ARI time series as a function of sample size. The bold contours in (a) and (b) indicate the boundaries of the monsoon domain. (a) As in Wang and Ding (2006), but using the combination of three datasets (see text). Each colored line of (d) corresponds to the ARI of one realization. 

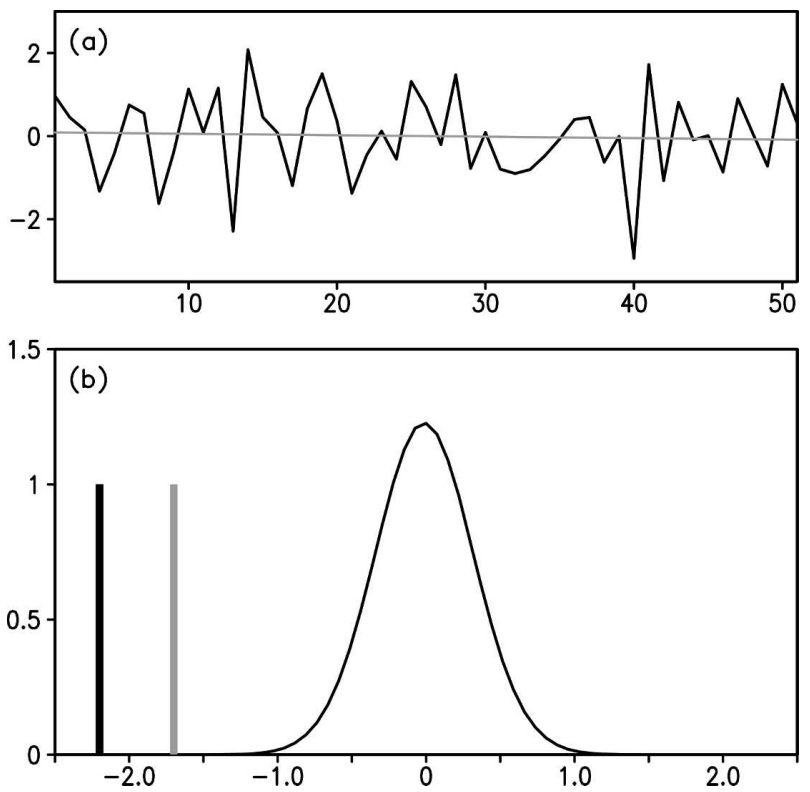

FIG. 6. (a) The normalized principle component of EOF1 mode of GCM simulated annual range anomalies over global land monsoon regions and (b) the corresponding empirical PDFs of annual range index trends. The data are from the 52 -yr control run of the CAM2 model forced with climatological SSTs. The trend value from 15 individual members of the AGCM simulations forced with the history of global observed SSTs is indicated by the gray bar. The observed trend value is indicated by the black bar.

plitude of the signal-to-noise ratio change is small, as evidenced in Fig. 5e.

To confirm the decreasing tendency of the simulated ARI shown in Fig. $5 \mathrm{c}$ is a forced signal, we employ another widely accepted method to test the effect of SSTs in the AMIP-type run. We investigate the difference of the CAM2 simulation between the forcing run driven by $52-\mathrm{yr}$ historical SST and the control run forced by the climatological SST. The origin of global monsoon rainfall variability can be clearly identified in this comparison. The ARI index of the control run was calculated by projecting the simulated anomalies onto the EOF1 pattern shown in Fig. 5b. As shown in Fig. 6a, no significant long-term trend is seen in the ARI index time series of the control run. Since the expected longterm trend of global monsoon rainfall is well captured in the forcing run, but not in the control run, we are confident of the effect of SST forcing in triggering this long-term trend.

We also employ a probability density function (PDF) approach to compare the roles of natural variation and external SST forcing. As shown in Fig. 6b, the trend of global land monsoon rainfall in the forcing run falls outside the control run's PDF. This supports the possibility that the land monsoon rainfall trends in the forc- ing run should not be the consequence of natural variability. In addition, the drying trend yielded by the forcing run is less than that of the observation (cf. the black and gray bar in Fig. 6b), suggesting the observed drying trend might not have been uniquely determined by the global SSTs.

In addition, the EOF2 mode of observation accounts for $7.5 \%$ of the total variance and mainly reflects an interannual variation of the global land monsoon rainfall, with centers in South Africa and North Australia (figures not shown here). Further comparison found little correspondence between the observation and the simulation in this mode (figures omitted).

Figure 7 presents the statistical significance of the observed and the simulated AR trend at each grid point within the land monsoon domain. To facilitate the comparison with observational analysis of Wang and Ding (2006), two methods were used to test the significance of linear trends: the trend-to-noise ratio, shown in Figs. 7a,c, and Mann-Kendall rank statistics (Sneyers 1990), illustrated in Figs. 7b,d. The significant spatial patterns detected by the two methods are consistent. A strong decreasing trend in monsoon rain intensity was found for northern Africa, the Bangladesh-northern Indiaeastern Tibetan Plateau, northern China, part of central South America, and the southern part of South Africa. An increasing trend in monsoon strength was seen over northwestern Australia, and central China along the Yangtze River valley (Figs. 7a,b). The decadal shift of mid-lower Yellow River valley $\left(34^{\circ}-40^{\circ} \mathrm{N}\right)$ drought and excessive rain in the Yangtze River valley of China has been reported in many previous observational analyses (e.g., Hu et al. 2003; Yu et al. 2004; Yu and Zhou 2007). The simulated features generally matched the observation. The simulated increasing trend in monsoon rain intensity over Madagascar is consistent with the observation. However, the observed decreasing trend over northern China is not evident in the simulation. The decreasing monsoon strength seen over northwestern Australia (Fig. 7) is in contrast to the observation. The simulated increasing trend over India and the northern Indochina peninsula is absent in the observation. Thus, the Asian monsoon rain intensity has the lowest reproducibility with prescribed SST forcing. The internal noise overlaps the SST-forced signal over these monsoon domains.

Over the Asian summer monsoon and Australian summer monsoon, the monsoon-ocean interaction has been recognized as a major source of the variability (Wang et al. 2000; Lau et al. 2004; Wang et al. 2003), and numerical simulation by 11 AGCMs was shown to fail in the simulation of the summer precipitation during the 1997-98 ENSO events (Wang et al. 2004). A 

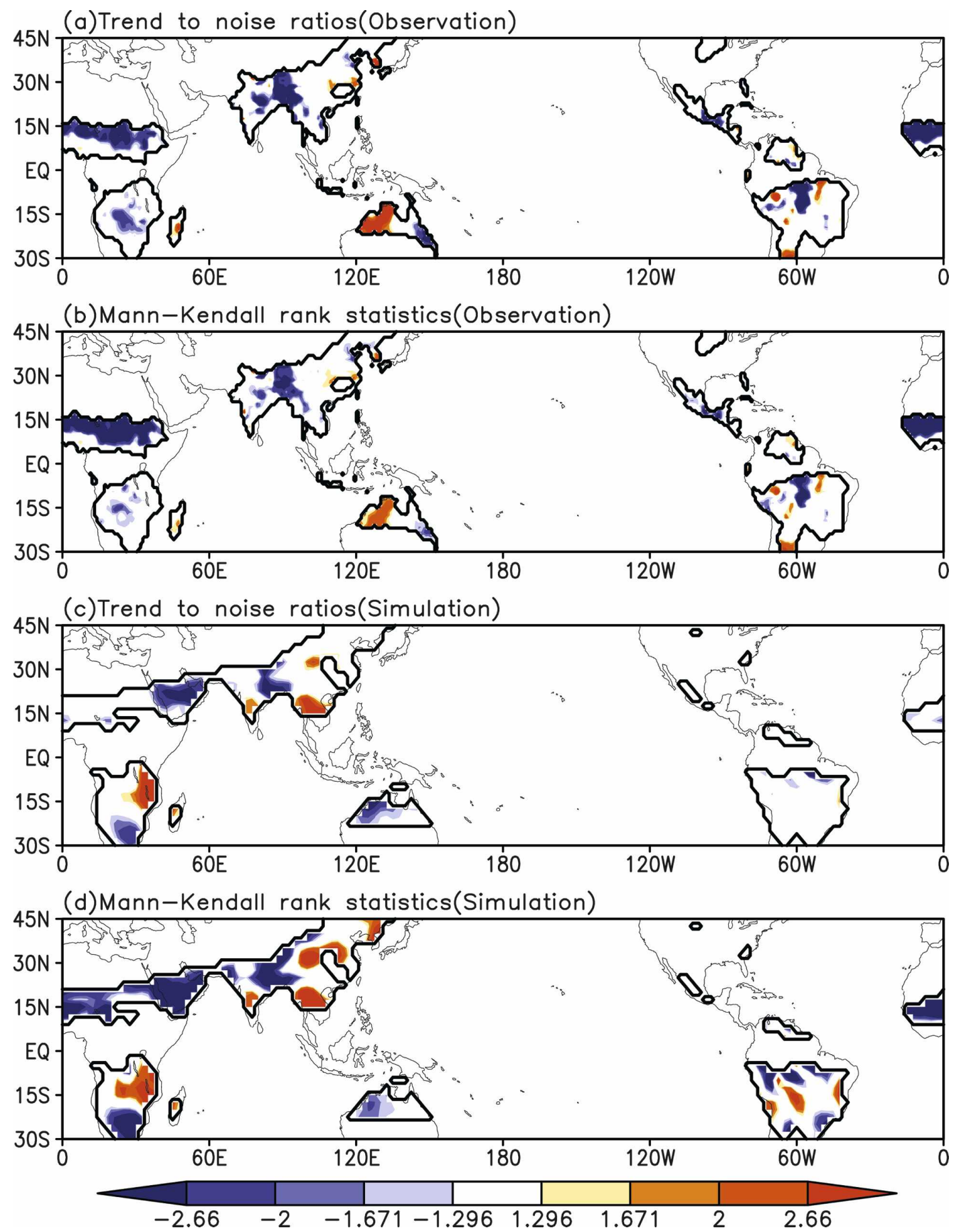

FIG. 7. Statistical significance of the linear trends in summer monsoon precipitation at each grid point in (a), (b) the observation and (c), (d) the ensemble of 15 realizations of the CAM2 simulation. Both (a) and (c) are for trend-to-noise ratio and (b) and (d) are for Mann-Kendal rank statistics.

five-AGCM ensemble hindcast experiment for a 21-yr period confirms that given SST forcing the multimodel ensemble is unable to predict the summer precipitation in the Asian monsoon region with useful skill (Wang et al. 2005). Hence coupled ocean-atmosphere processes are crucial in the Asian-Australian monsoon regions where atmospheric feedback on SST is very significant; thus, treating the monsoon as a slave would result in the models' failure (Wang et al. 2005; Wu and Kirtman 2007). The neglect of atmospheric feedback makes the 


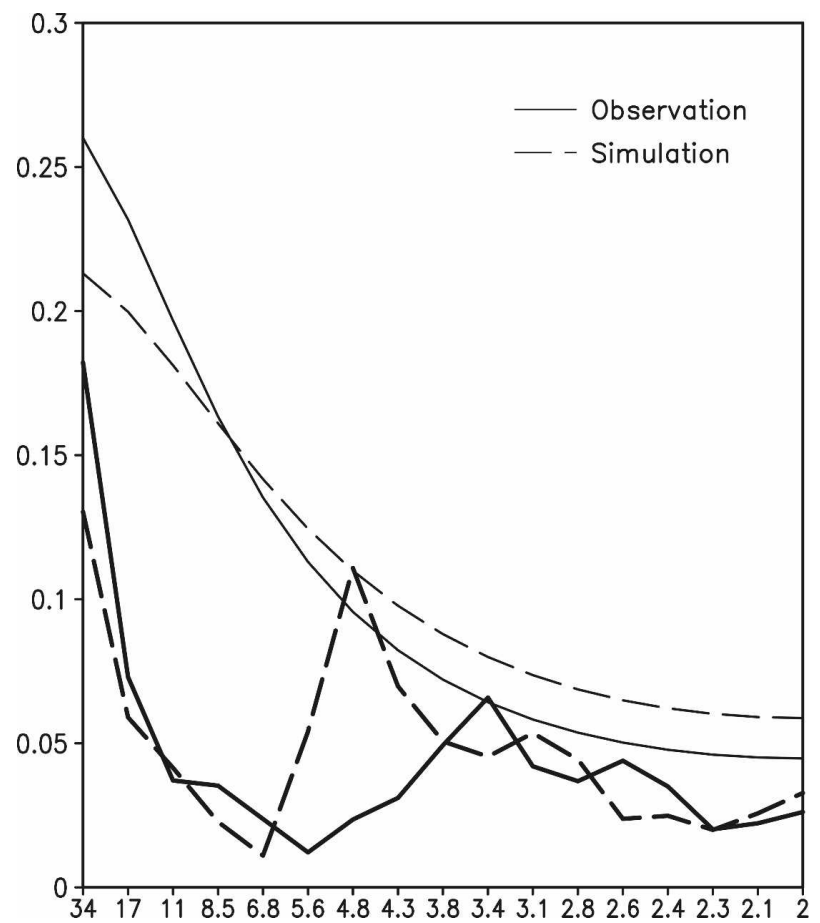

FIG. 8. Power spectra of the observed (solid line) and simulated (dashed line) annual range index represented by the principal component of leading EOF mode of the normalized annual range anomalies. The thin line is the red noise power density. A spectrum with a peak above the thin line distinguishes it from a red noise spectrum with a confidence level over $95 \%$.

forced solution depart from the coupled solution over part of the Asian-Australian monsoon region, as also suggested by the model results presented here.

\section{c. The oceanic forcing of precipitation changes over the land monsoon domain}

In addition to the linear trend, the observational ARI also shows significant interannual to interdecadal variability (Fig. 5c). After linear detrending, the time series of the leading principle component of the ensemble simulation has a correlation coefficient of 0.43 with the observation, which is statistically significant at the $5 \%$ level, indicating that the interannual variability of the observational ARI can be partly reproduced by prescribing the observational SST forcing to the CAM2 model.

The power spectra of the time series of the first principle component for both the observation and the simulation are shown in Fig. 8. The principle component (hereinafter PC1) of the observation has double spectral peaks on 2.5 and $3.5 \mathrm{yr}$, respectively. The $3.5-\mathrm{yr}$ peak seems more significant than the 2.5 -yr peak. The simultaneous correlation coefficient between the PC1 and the Niño-3.4 index (a measure of ENSO intensity, which is defined as SST anomalies averaged within the box of $5^{\circ} \mathrm{S}-5^{\circ} \mathrm{N}, 120^{\circ}-170^{\circ} \mathrm{W}$ ) reaches -0.43 in the observation, indicating that the leading mode of the annual range of land monsoon precipitation concurs with ENSO. The PC1 of the simulation exhibits a single spectral peak around the center of $4.8 \mathrm{yr}$; the peak around $3.0 \mathrm{yr}$ is very weak. The relationship between the time series of PC1 and the Niño-3.4 index in simulation is comparable to the observation, having a slightly stronger simultaneous correlation coefficient of -0.70 . A wavelet analysis reveals that the $4.8-\mathrm{yr}$ oscillation is more evident in the post-1970 period (figure not shown here). The spectra difference between the observation and simulation is not unexpected, since only SST forcing was prescribed in the model simulation, while in the real world the observed rainfall variation was also disturbed by other forcing mechanisms such as land surface processes acting to supplement the ocean forcing (see Yang and Lau 2006 for a review).

To further reveal whether the interannual variation of the ARI significantly relates to ENSO, the spatial distribution of the correlation coefficient between the observed JJA SST anomalies and the time series of PC1 is shown in Fig. 9a. To eliminate the contribution from linear trends, the time series of PC1 has been detrended before the calculation. The local SST anomalies and the time series of $\mathrm{PC} 1$ are negatively correlated in the tropical eastern-central Pacific. The correlations are positive in the western North and South Pacific and the tropical eastern Indian Ocean. Significant positive correlations are also observed in part of the tropical Atlantic Ocean. The SST-PC1 correlations in the CAM2 simulation agree well with the observations (Fig. 9b). In particular, over the tropical eastern-central Pacific the observed correlation coefficient is about -0.40 while in the simulation it is about -0.60 ; over the western South Pacific, the observed correlation coefficient is beyond 0.25 , while in the simulation, it is even higher than 0.4 They are all statistically significant at the $5 \%$ level. The close resemblance between the observation and the simulation indicates the dominance of oceanic forcing in the interannual AR variability. This consistency also suggests that if tropical SSTs are known and prescribed to an atmospheric general circulation model, there would be some predictability of the interannual variability of the AR.

In addition to the interannual variation, the most dominant feature of the time series of the principal component of AR shown in Fig. 5c is the decreasing tendency in the past decades. The consistency between the simulation and the observation indicates the driving mechanism of the oceanic forcing in producing this 


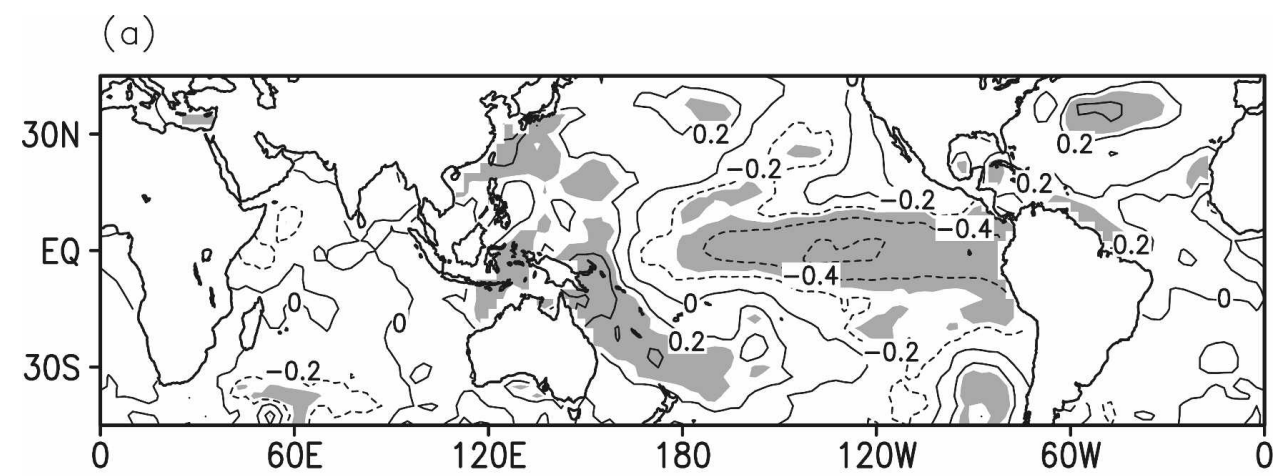

(b)

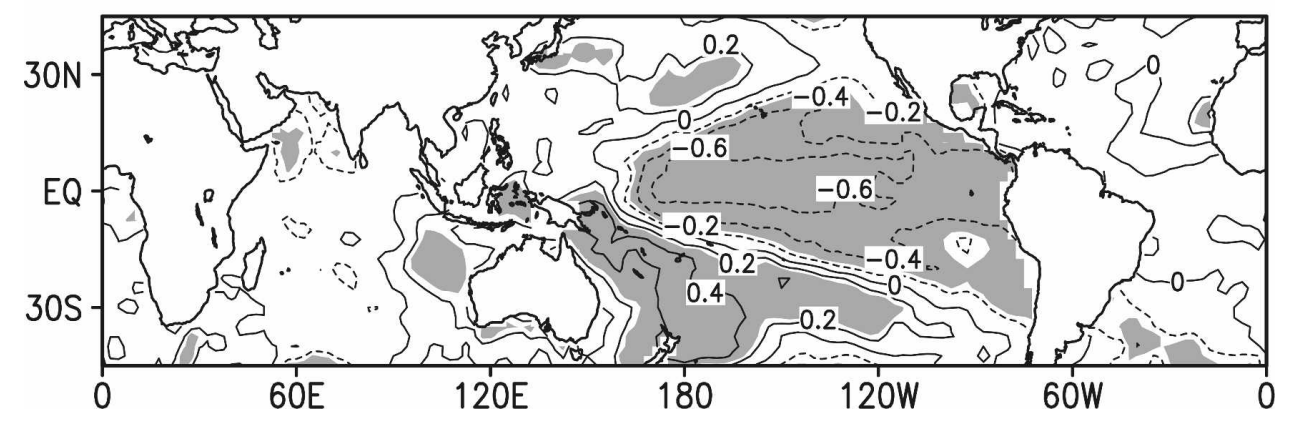

FIG. 9. Distribution of simultaneous correlation coefficients between the time series of the leading principal component of AR and JJA SST anomalies: (a) observation and (b) simulation. Areas exceeding confidence limit of $5 \%$ are shaded.

trend. Significant warming trends are observed in the summertime SST anomalies over the central-eastern tropical Pacific and tropical southern Atlantic; the warming of the tropical Indian Ocean is spatially amorphous and of the same polarity throughout the basin (Fig. 10a). Following Thompson et al. (2000), the linear trends are estimated as the slope of a straight line fitted (in a least squares sense) to the observed SST data at each grid point based on the reference periods defined. To reveal which part of the observed oceanic warming accounts for the decreasing trend of the time series of AR PC1, the observed SST anomalies trends can be partitioned into linearly congruent and linearly independent components with respect to the AR PC1 time series. The component of SST trends that is linearly congruent with the PC1 time series is estimated at each grid point by regressing values of that grid point's time series onto the PC1 time series, and then multiplying the resulting regression coefficients by the linear trend in the PC1 time series (Thompson et al. 2000).

Significant warming trends are observed over the central-eastern tropical Pacific and the tropical Indian Ocean (Fig. 10b). A close resemblance is found between the PC1-congruent component and the total trend over the tropical oceans. It is the warming of the central-eastern Pacific and the tropical Indian Ocean that contributes to the decreasing tends of time series of AR PC1. The warming trend of the western northern Pacific produces little positive contribution. A moderate contribution from the recent warming of the tropical South Atlantic is seen. The structural similarity between the observation and the simulation in the PC1congruent components of SST trends is striking (cf. Figs. 10b,c), although the meridional shape of the central-eastern Pacific warming in the simulation is wider than that of the observation. The amplitude of the warming over the central-eastern Pacific in the simulation is comparable to that of the observation.

\section{d. Changes of precipitation intensity over the oceanic monsoon domain}

By using the GPCP dataset, Wang and Ding (2006) found that there was an increasing trend over the oceanic summer monsoon region since 1979 , while no significant trend was detected for the global land monsoon region during the same period. What about the precipitation change over the oceanic monsoon region in the CAM2 simulation? To answer this question, anomalies of the global monsoon indices over the ocean area are 


\section{(a)}

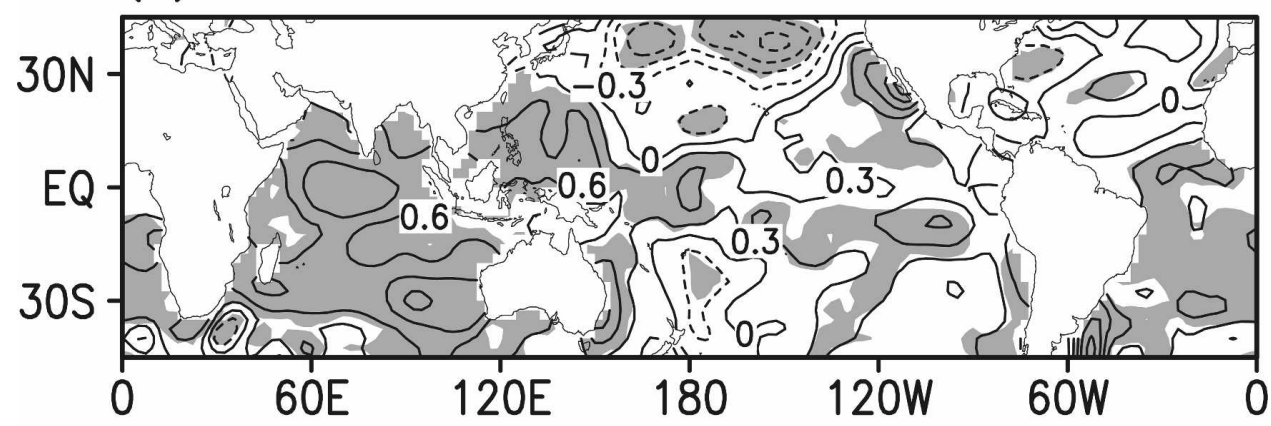

(b)

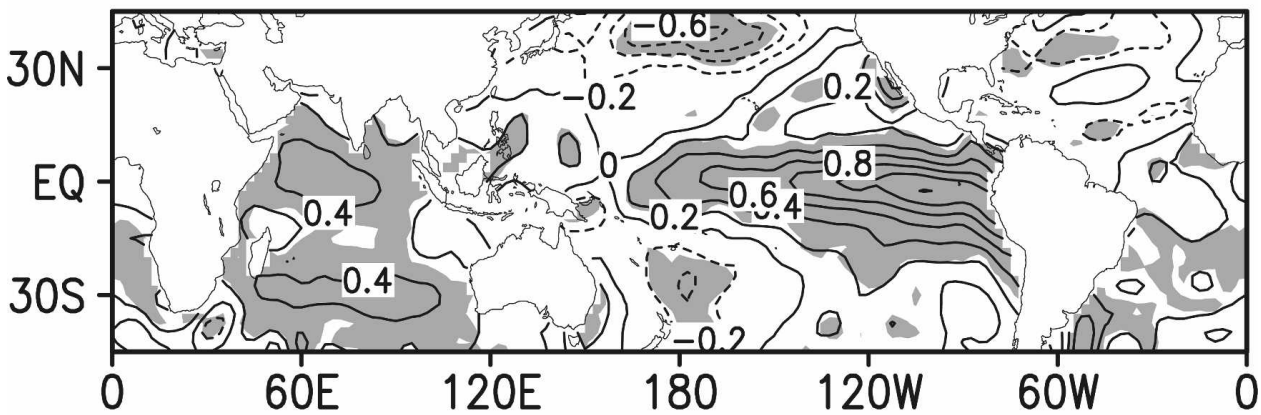

(c)

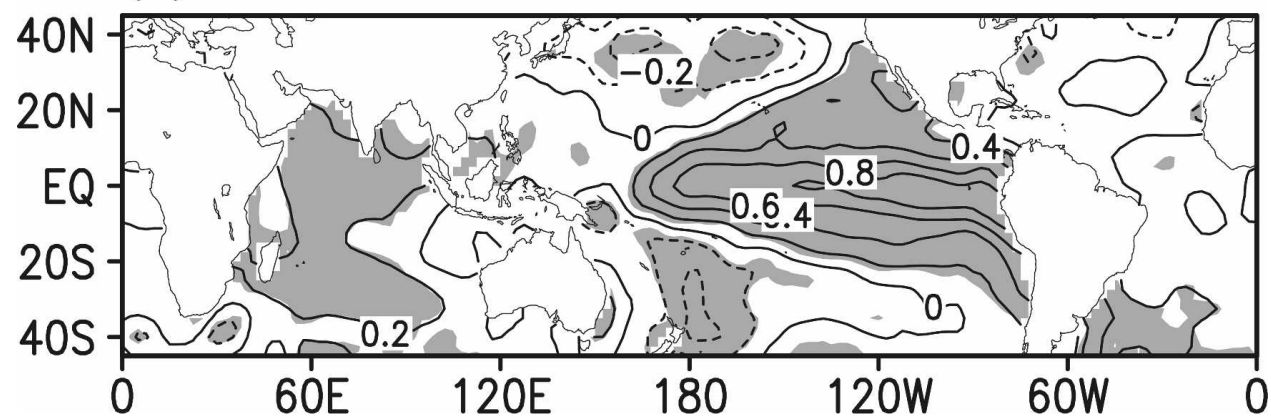

FIG. 10. (a) Linear trends of JJA SST anomalies and the components linearly congruent with the PC1 time series of AR for (b) the observation and (c) the simulation. Areas exceeding the confidence limit of $5 \%$ using the $f$ test are shaded. Units are ${ }^{\circ} \mathrm{C}(50 \mathrm{yr})^{-1}$.

shown in Fig. 11a. The global monsoon indices over the land during the same period are also drawn in Fig. 11b for comparison. The model results are presented paralleling those of the observations.

In addition to the GPCP data, the CMAP dataset also provides global precipitation measurements over the last $25 \mathrm{yr}$, charted on a $2.5^{\circ}$ by $2.5^{\circ}$ grid (Xie and Arkin 1996). The climatological, global averaged precipitation rate is $2.67 \mathrm{~mm}$ day $^{-1}$, with a tiny yearly standard deviation of $0.04 \mathrm{~mm} \mathrm{day}^{-1}$; both are comparable to the GPCP data, which is 2.61 and $0.03 \mathrm{~mm}^{-1 a y}{ }^{-1}$, respectively (Wang and Ding 2006). The climatological mean precipitation rate over the land monsoon area over the last $22 \mathrm{yr}(1979-2000)$ is $6.37 \mathrm{~mm} \mathrm{day}^{-1}$ in merged rain gauge observation, $6.04 \mathrm{~mm} \mathrm{day}^{-1}$ in CMAP data, $6.12 \mathrm{~mm} \mathrm{day}^{-1}$ in GPCP data, and 6.34 $\mathrm{mm} \mathrm{day}^{-1}$ in the simulation. The corresponding climatological mean value over the ocean monsoon area is $6.54 \mathrm{~mm} \mathrm{day}^{-1}$ in GPCP data, $7.77 \mathrm{~mm}$ day $^{-1}$ in CMAP data, and $7.18 \mathrm{~mm} \mathrm{day}^{-1}$ in the simulation. The bias of the model in simulating the climatological mean monsoon precipitation is small, having a value within the scope of data uncertainties.

It is surprising to see that there is very little correspondence between the simulation and the observation in the global monsoon index over the ocean area (Fig. 


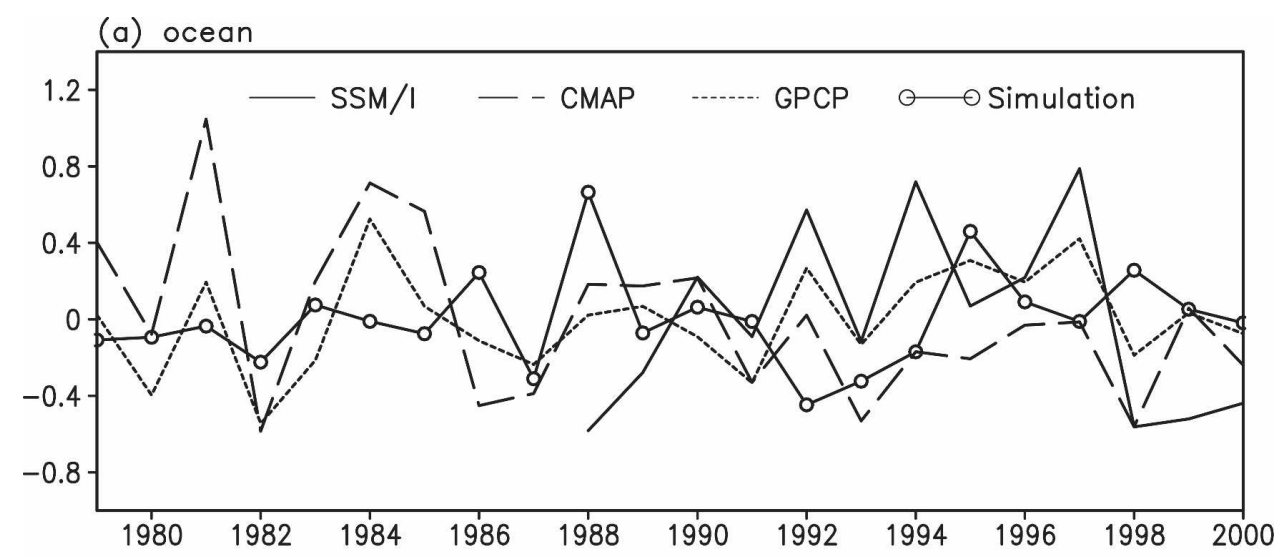

(b) land

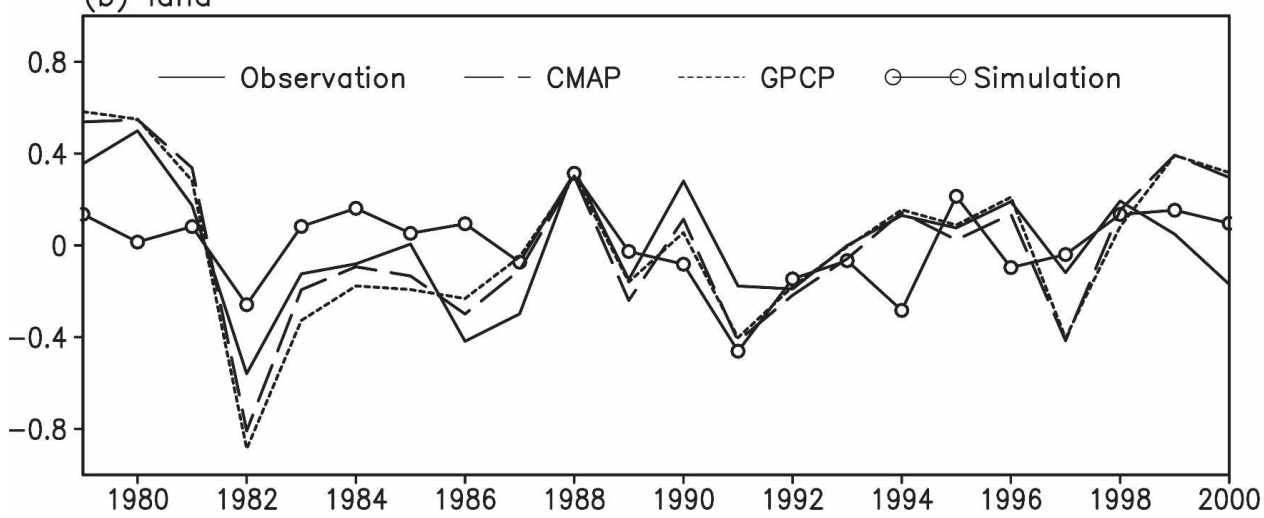

FIG. 11. The GMI over the (a) ocean and (b) land region. The data used are the GPCP data (19792000), CMAP data (1979-2000), SSM/I data (1988-2000), and the ensemble mean of 15 realizations of CAM2 simulation. Also shown in (b) is the GMI over the land region, derived from the ensemble land-based rain gauge data. Units are $\mathrm{mm} \mathrm{day}^{-1}$.

11a). The simulated oceanic monsoon index has a correlation coefficient of 0.13 with the index derived from the GPCP data, which is not statistically significant at the $5 \%$ confidence level. In particular, no apparent increasing trend is seen in the simulated oceanic monsoon index (Fig. 11a). This discrepancy might arise from the uncertainty of observational data. As shown in Table 1, the correlation between the simulation and the CMAP observation is even lower (i.e., 0.05). While the GPCP data shows an increasing trend of $0.55 \mathrm{~mm} \mathrm{day}^{-1}$ $(50 \mathrm{yr})^{-1}$ for the period 1979-2000 in the oceanic monsoon index, similar trends cannot be observed in the CMAP data [the corresponding trend is $-1.4 \mathrm{~mm} \mathrm{day}^{-1}$ $(50 \mathrm{yr})^{-1}$ ].

In addition to the GPCP and CMAP data, the SSM/I estimates might be the best available precipitation estimates over the ocean (Wentz and Spencer 1998) and should serve as a useful validation of the other data. Since the SSM/I estimates are only available from 1988 to the present, we show the statistics on the variation of oceanic monsoon rainfall for the period $1988-2000$ in Table 1 (see the values in parentheses). The oceanic monsoon index derived from SSM/I is highly correlated with that of the GPCP data, having a correlation coef-

TABLE 1. Correlation coefficients among the observed and the simulated oceanic and global monsoon indices during 1979-2000. The values in parentheses for SSM/I are for the period covering 1988-2000.

\begin{tabular}{lccc}
\hline \hline & $\begin{array}{c}\text { GPCP } \\
\text { ocean }\end{array}$ & $\begin{array}{c}\text { CMAP } \\
\text { ocean }\end{array}$ & $\begin{array}{c}\text { Simulated } \\
\text { ocean }\end{array}$ \\
\hline GPCP ocean & 1.0 & 0.54 & 0.13 \\
CMAP ocean & 0.54 & 1.0 & 0.05 \\
SSM/I & $(0.63)$ & $(0.16)$ & $(-0.48)$ \\
Simulated ocean & 0.13 & 0.05 & 1.0 \\
& GPCP & CMAP & Simulated \\
& global & global & global \\
\hline GPCP global & 1.0 & 0.78 & 0.40 \\
CMAP global & 0.78 & 1.0 & 0.35 \\
Simulated global & 0.40 & 0.35 & 1.0 \\
\hline
\end{tabular}


TABLE 2. Correlation coefficients among the observed and the simulated land monsoon indices during 1979-2000.

\begin{tabular}{llllc}
\hline \hline & $\begin{array}{c}\text { Obs } \\
\text { land }\end{array}$ & $\begin{array}{c}\text { GPCP } \\
\text { land }\end{array}$ & $\begin{array}{c}\text { CMAP } \\
\text { land }\end{array}$ & $\begin{array}{c}\text { Simulated } \\
\text { land }\end{array}$ \\
\hline Obs land & 1.0 & 0.80 & 0.84 & 0.36 \\
GPCP land & 0.80 & 1.0 & 0.98 & 0.48 \\
CMAP land & 0.84 & 0.98 & 1.0 & 0.52 \\
Simulated land & 0.36 & 0.48 & 0.52 & 1.0 \\
\hline
\end{tabular}

ficient of 0.63 . The correlation of the two indices derived from the SSM/I and CMAP datasets is extremely low (i.e., 0.16) and not statistically significant at the $5 \%$ level. Thus the GPCP is probably a more reliable estimate of rainfall than CMAP. The correlation of oceanic monsoon indices derived from the simulation and $\mathrm{SSM} / \mathrm{I}$ data is still poor. Although the data length of $\mathrm{SSM} / \mathrm{I}$ is not long enough to accurately estimate a trend, a comparison with the other data still has the value of reference. The SSM/I data shows a trend of $0.52 \mathrm{~mm}$ day $^{-1}(50 \mathrm{yr})^{-1}$ for the period 1988-99 in the oceanic monsoon index. This value is larger than that of the GPCP data, which is $0.39 \mathrm{~mm}^{\text {day }}{ }^{-1}(50 \mathrm{yr})^{-1}$. Thus, the consistency of different datasets in estimating the oceanic monsoon rainfall trends is not satisfactory. The poor simulation of the ocean monsoon index might arise from data uncertainties. Nevertheless, discrepancies of the CAM2 model in describing the ocean monsoon domain should also have contributions to the low reproducibility (see Fig. 2a).

In contrast to the global monsoon index over the ocean area, the global land monsoon indices derived from two satellite datasets are highly correlated, having a correlation coefficient of 0.98 (Table 2). The land monsoon index derived from the GPCP (CMAP) data has a correlation coefficient of $0.80(0.84)$ with the rain gauge data derived index. The reliability of the satellite data over the land monsoon area is better than that over the oceanic monsoon region. Both the CMAP and the GPCP precipitation are estimates based on satellite data and in situ observations on land (Xie and Arkin 1996; Huffman et al. 1997; Adler et al. 2003). Because of different algorithms used to retrieve the rainfall from the satellite data, there are some distinctive differences between these two datasets over the ocean regions (Gruber et al. 2000). There is a possibility that the observational evidence over the oceanic monsoon area might not be solid enough for evaluating climate models, in particular for the long-term variability. If this is true, great efforts should be devoted to improving the qualities of precipitation products over the ocean area.

\section{Concluding remarks}

\section{a. Conclusions}

The global monsoon rainfall over land has an overall weakening trend over the last half-century (1950-2000). Causes for this observed decreasing tendency are addressed by analyzing the output of ensemble simulations of the NCAR CAM2 model forced by historical sea surface temperature. The main results are summarized below.

1) The CAM 2 model has reasonable performances in simulating the observed major monsoon rainy regions, which include the northern African and southern African monsoon region, the South and East Asian monsoon region, the Australian monsoon region, and the Central American and southern American monsoon region except for the western Pacific rainy region. The deficiency of the model in producing the rainy regions over the central tropical South Pacific is partly ascribed to the ill-simulated double ITCZ.

2) The significant changes of global land monsoon rainfall are deducible from the atmosphere's response to the observed SST variations. Since the signal of external SST forcing is larger than the noise caused by internal atmospheric dynamics, the observational decreasing trend in the Northern Hemisphere monsoon index has been reproduced by the CAM2 simulation. There are significant correlations between the simulated and the observed global land monsoon precipitation indices, indicating that most of the observational land monsoon rainfall variability arises from the oceanic forcing.

3) The majority of the land monsoon region shows a coherent decreasing tendency, with the largest amplitude over northern Africa. This typical feature has been well produced in the ensemble simulation except for the Asian monsoon rain intensity. The observed drying trend is attributable to a common oceanic influence (i.e., the recent warming over the central-eastern Pacific and the tropical Indian Ocean).

4) The interannual variation of the ARI significantly relates to ENSO. The leading mode of the annual range of land monsoon precipitation concurs with ENSO. Prescribing the observational SST forcing to the CAM2 model successfully captures the interannual variation of the ARI, except for some differences in the spectral peaks.

5) There are uncertainties between the GPCP and CMAP data in describing the evolution of global ocean monsoon precipitation. There exists very little 
correspondence between the simulated and the observed global monsoon index over the ocean area. Uncertainties in the satellite data and model deficiencies in describing the ocean monsoon domain are partly to blame.

\section{b. Discussion}

Studying how monsoon rains have changed may provide insight for understanding future changes. Current state-of-the-art climate models are imperfect and are not the real atmosphere. If the presented model results provide a reliable indication of the behavior of the real world, then they have implications for the interpretation of long-term global land monsoon rainfall change. The evidence from our results suggests the key roles of SST anomalies in the tropical Pacific and Indian Ocean. The warming trend across the Indo-Pacific Ocean perhaps also reflects the eastern Pacific SST forcing on the Indian Ocean, as in the case of climate variability in which ENSO forces the Indian Ocean monopole (Klein et al. 1999; Lau and Nath 2003; Yang et al. 2006). Further work to identify and understand the causes of these SST anomalies will also have implications for projections of global land monsoon rainfall change, particularly its response to global warming. In addition, this analysis focuses on typical summer and winter monsoon seasons only. During boreal fall the convection maximum occurs in the eastern Indian Ocean, the Malay Peninsula and Sumatra, and the southern South China Sea, hence a large amount of rainfall also falls in Southeast Asia during this transition season (Chang et al. 2005). The long-term trend of monsoon rainfall during the transition season will be analyzed in a separate paper.

It is important to acknowledge the limitations of this study. In particular, we have used a prescribed SST boundary condition. Several studies have pointed out that one must be cautious in using AGCM studies with prescribed SSTs to interpret the influence of the extratropical oceans on climate variability (e.g., Sutton and Hodson 2007). Recent studies suggested that the monsoon simulation strongly depends on the correct air-sea coupling over the Asian-Australian monsoon region (Wang et al. 2005; Wu et al. 2006; Wu and Kirtman 2007). In the tropical Indo-western Pacific Ocean regions, SST forcing and atmospheric forcing dominate alternatively in different seasons. Atmospheric forcing dominates in the local warm/rainy season ( $\mathrm{Wu}$ and Kirtman 2007). The performance of SST-forced simulation is low or poor when atmospheric forcing dominates; coupling an AGCM with an ocean model can better simulate the Asian summer monsoon climatology (Fu et al. 2002). The result of the SST-forced run presented here is mainly successful at capturing the observed long-term trend of monsoon rainfall over northern and southern Africa, South America, eastern Australia, Bangladesh-northern India-eastern Tibetan Plateau, and part of northern China, except for the rainfall trend over southern Asia, and western Australia (cf. Figs. 5a,b). With the inclusion of the air-sea feedback, whether it is possible to correctly simulate the longterm trend of summer monsoon rainfall over this region warrants further study. Kim et al. (2008, manuscript submitted to J. Climate) evaluated the twentieth century Coupled Climate Model simulations for the period of 1951-99 collected from the World Climate Research Programme's Coupled Model Intercomparison Project phase 3 (CMIP3) multimodel dataset. They found that regardless of the prescribed external forcing, none of the models is able to faithfully simulate the observed decreasing tendency in the Northern Hemisphere land monsoon domain. As an extension of AMIP-type run, the "partial-coupling" approach may help us to further understand the mechanism. For this purpose, the lower boundary conditions surrounding the maritime sites outside the tropical Pacific are either set to an oceanic mixed layer model or an oceanic general circulation model, while observed monthly SST variations are prescribed in the tropical Pacific, as has been done in the simulation of interannual variability of the AsianAustralian monsoon (Lau and Nath 2000, 2003, 2006).

Another potential limitation is the definition of monsoon domains. The monsoon not only exhibits changes in rainfall intensity, but also experiences changes in coverage. The monsoon domains can migrate spatially over time with changes in internal and external forcing agents of the coupled system. Since the monsoon index was calculated as the average of precipitation intensity falling within the climatological annual range-defined monsoon region as Wang and Ding (2006), it is unable to describe the changes of area covered by monsoon rain. There has been a substantial change in land-sea thermal contrast over the past $52 \mathrm{yr}$; the monsoon domain should have been affected by the change of thermal contrast. For example, Kitoh et al. (1997) raised an important issue about an apparent paradox between the South Asian summer monsoon's increasing precipitation and its decreasing circulation intensity. This paradox is explained by the northward shift of the monsoon circulation (see also Kitoh 2006 for a review). Thus, the migration of the monsoon domain might not be correctly interpretated by simply using an increasing or reduction of monsoon precipitation. A more robust analysis approach, which is capable of quantifying the migration of monsoon domain, needs to be developed. 
One potential caveat of this work is the experimental design, since only the historical SST variation was prescribed. In nature, however, both natural and anthropogenic forcing agents contribute to the monsoon rainfall change (e.g., Meehl and Washington 1993; Yu et al. 2004; Li et al. 2005; Kitoh and Uchiyama 2006; Xin et al. 2006; Yang and Lau 2006). Previous studies have speculated that man-made absorbing aerosols in remote populous industrial regions alter regional atmospheric circulation and cause regional climate change (e.g., Qian and Giorgi 1999; Qian et al. 2001). Recent studies suggested that sulfate and black carbon aerosols have played a role in forcing the recent changes in monsoon rains by cooling the surface or reduce the latitudinal SST gradient (Menon et al. 2002; Lau et al. 2006; Meehl et al. 2008). However, the responses of climate models to the inclusion of aerosols are model-dependent. For example, Menon et al. (2002) suggest that precipitation trends in China over the past several decades may be related to the increased Black carbon aerosols. Meehl et al. (2008) argue that the observed increasing precipitation trends over southern China appear to be associated with natural variability connected to surface temperature changes in the northwest Pacific. The inclusion of aerosols seems to suppress the simulated increasing trends in Southeast Asia as seen in many general circulation model simulations (e.g., Mitchell and Johns 1997), but not in all (e.g., Roeckner et al. 1999). A spread is also seen in the surface air temperature responses to prescribed forcing agents including aerosols simulated by 19 coupled models involved in the CMIP3 project (Zhou and Yu 2006). Nonetheless, our suggestion of the contribution of tropical ocean warming to the decreasing tendency of global land monsoon rainfall does not rule out any other factors. There is a need to better understand the roles of other forcing agents including aerosols as potential causes of global monsoon rainfall variation.

In addition, we have carried out analyses with the single atmospheric model CAM2. Whether other models can yield consistent climate responses with respect to main features reported here warrants further study. A set of such comparisons will be taken as part of the Climate Variability and Predictability (CLIVAR) International Climate of the Twentieth Century Project (C20C; Folland et al. 2002). Such multimodel intercomparisons should help us to gain insight on the forcing mechanisms of global monsoon rainfall variation. The present results provide a useful reference for the future multimodel assessment of C20C.

Acknowledgments. This work was jointly supported by the National Basic Research Program of China
(2006CB403603 and 2005CB321703); the National Natural Science Foundation of China under Grants 40628006, 40625014, and 40675050; and the Chinese Academy of Sciences International Partnership Creative Group titled "The Climate System Model Development and Application Studies." We appreciate the NCAR climate variability working group for providing the model outputs. We thank Ms. Lixiang Zhang for treating the SSM/I data and revising relevant figures. The helpful suggestions from the three anonymous reviewers and the editor, Dr. James Renwick, are also gratefully acknowledged.

\section{REFERENCES}

Adler, R., and Coauthors, 2003: The version 2 Global Precipitation Climatology Project (GPCP) monthly precipitation analysis (1979-Present). J. Hydrometeor., 4, 1147-1167.

Chang, C. P., Z. Wang, J. McBride, and C. Liu, 2005: Annual cycle of Southeast Asia-Maritime continent rainfall and the asymmetric monsoon transition. J. Climate, 18, 287-301.

Chase, T., J. Knaff, R. Pielke Sr., and E. Kalnay, 2003: Changes in global monsoon circulations since 1950. Nat. Hazards, 29, 229-254.

Chen, M., P. Xie, J. Janowiak, and P. Arkin, 2002: Global land precipitation: A 50-yr monthly analysis based on gauge observations. J. Hydrometeor., 3, 249-266.

Folland, C., J. Shukla, J. Kinter, and M. Rodwell, 2002: C20C: The climate of the twentieth century project, CLIVAR Exchanges, No. 7, International CLIVAR Project Office, Southhampton, United Kingdom, 37-39. [Available online at http://eprints.soton.ac.uk/19305/01/ex24.pdf]

$\mathrm{Fu}, \mathrm{X}$., B. Wang, and T. Li, 2002: Impacts of air-sea coupling on the simulation of mean Asian summer monsoon in the ECHAM4 model. Mon. Wea. Rev., 130, 2889-2904.

Gruber, A., X. Su, M. Kanamitsu, J. Schemm, 2000: The comparison of two merged rain gauge-satellite precipitation datasets. Bull. Amer. Meteor. Soc., 81, 2631-2644.

Hoerling, M., J. Hurrell, J. Eischeid, and A. Phillips, 2006: Detection and attribution of twentieth-century northern and southern African rainfall change. J. Climate, 19, 3989-4008.

Hu, Z., 1997: Interdecadal variability of summer climate over East Asia and its association with $500 \mathrm{hPa}$ height and global sea surface temperature. J. Geophys. Res., 102, 19 403-19 412.

—, S. Yang, and R. Wu, 2003: Long-term climate variations in China and global warming signals. J. Geophys. Res., 108, 4614, doi:10.1029/2003JD003651.

Huffman, G. J., and Coauthors, 1997: The Global Precipitation Climatology Project (GPCP) combined precipitation dataset. Bull. Amer. Meteor. Soc., 78, 5-20.

Hulme, M., 1996: Recent climatic change in the world's drylands. Geophys. Res. Lett., 23, 61-64.

, T. J. Osborn, and T. C. Johns, 1998: Precipitation sensitivity to global warming: Comparison of observations with HadCM2 simulations. Geophys. Res. Lett., 25, 3379-3382.

Hurrell, J. W., J. J. Hack, D. Shea, J. M. Caron, and J. Rosinski, 2008: A new sea surface temperature and sea ice boundary dataset for the community atmosphere model. J. Climate, in press. 
Kim, H., B. Wang, and Q. Ding, 2008: The global monsoon variability simulated by CMIP3 coupled climate models. J. Climate, in press.

Kitoh, A., 2006: Asian monsoons in the future. The Asian Monsoon, B. Wang, Ed., Springer-Praxis, 631-649.

- and T. Uchiyama, 2006: Changes in onset and withdrawal of the East Asian summer rainy season by multi-model global warming experiments. J. Meteor. Soc. Japan, 84, 247-258.

— S. Yukimoto, A. Noda, and T. Motoi, 1997: Simulated changes in the Asian summer monsoon at times of increased atmospheric $\mathrm{CO}_{2}$. J. Meteor. Soc. Japan, 75, 1019-1031.

Klein, S., B. Soden, and N. Lau, 1999: Remote sea surface temperature variations during ENSO: Evidence for a tropical atmospheric bridge. J. Climate, 12, 917-932.

Kripalani, R., A. Kulkarni, S. Sabade, and M. Khandekar, 2003: Indian monsoon variability in a global warming scenario. Nat. Hazards, 29, 189-206.

Lau, K., M. Kim, and K. Kim, 2006: Asian summer monsoon anomalies induced by aerosol direct forcing: The role of the Tibetan Plateau. Climate Dyn., 26, 855-864.

Lau, N.-C., and M. J. Nath, 2000: Impact of ENSO on the variability of the Asian-Australian monsoons as simulated in GCM experiments. J. Climate, 13, 4287-4309.

- , and 2003: Atmosphere-Ocean variations in the IndoPacific sector during ENSO episodes. J. Climate, 16, 3-20.

- , and - 2006: ENSO modulation of the interannual and intraseasonal variability of the East Asian monsoonA model study. J. Climate, 19, 4508-4530.

,-- , and H. Wang, 2004: Simulation by a GFDL GCM of ENSO-related variability of the coupled ocean-atmosphere system in the East Asian monsoon region. East Asian Monsoon, C. P. Chang, Ed., World Scientific Series on Meteorology on East Asia, Vol. 2, World Scientific, 271-300.

Li, J., R. Yu, T. Zhou, and B. Wang, 2005: Why is there an early spring cooling shift downstream of the Tibetan Plateau? $J$. Climate, 18, 4660-4668.

Li, Z., 1999: Ensemble atmospheric GCM simulation of climate interannual variability from 1979 to 1994 . J. Climate, 12, 9861001.

Meehl, G., and W. Washington, 1993: South Asian summer monsoon variability in a model with doubled atmospheric carbon dioxide concentration. Science, 260, 1101-1104.

—, J. Arblaster, and W. Collins, 2008: Effects of black carbon aerosols on the Indian monsoon. J. Climate, 21, 2869-2882.

Menon, S., J. Hansen, L. Nazarenko, and Y. Luo, 2002: Climate effects of black carbon aerosols in China and India. Science, 297, 2250-2253.

Mitchell, J., and T. Johns, 1997: On modification of global warming by sulfate aerosols. J. Climate, 10, 245-267.

New, M., M. Hulme, and P. Jones, 1999: Representing twentiethcentury space-time climate variability. Part I: Development of a 1961-90 mean monthly terrestrial climatology. J. Climate, 12, 829-856.

Nitta, T., and Z. Hu, 1996: Summer climate variability in China and its association with $500 \mathrm{hPa}$ height and tropical convection. J. Meteor. Soc. Japan, 74, 425-445.

Qian, Y., and F. Giorgi, 1999: Interactive coupling of regional climate and sulfate aerosol models over eastern Asia. J. Geophys. Res., 104, 6477-6499.
— - _ Y. Yuang, W. L. Chameides, and C. Luo, 2001: Regional simulation of anthropogenic sulfur over East Asia and its sensitivity to model parameters. Tellus, 53B, 171-191.

Roeckner, E., L. Bengttson, J. Feichter, J. Lelieveld, and H. Rodhe, 1999: Transient climate change simulations with a coupled atmosphere-ocean GCM including the tropospheric sulfur cycle. J. Climate, 12, 3004-3032.

Sneyers, R., 1990: On the statistical analysis of series of observations. WMO Tech. Note 143, WMO 415, TP-103, World Meteorological Organization, $192 \mathrm{pp}$.

Sutton, R., and D. Hodson, 2007: Climate response to basin-scale warming and cooling of the North Atlantic Ocean. J. Climate, 20, 891-907.

Thompson, D., J. Wallace, and G. Hegerl, 2000: Annular modes in the extratropical circulation. Part II: Trends. J. Climate, 13, 1018-1036.

Trenberth, K., D. Stepaniak, and J. Caron, 2000: The global monsoon as seen through the divergent atmospheric circulation. J. Climate, 13, 3969-3993.

_- J. Hurrell, and D. Stepaniak, 2006: The Asian monsoon: Global perspective. The Asian Monsoon, B. Wang, Ed., Springer-Praxis, 67-87.

Wang, B., and H. Lin, 2002: Rainy season of the Asian-Pacific summer monsoon. J. Climate, 15, 386-398.

— , and Q. Ding, 2006: Changes in global monsoon precipitation over the past 56 years. Geophys. Res. Lett., 33, L06711, doi:10.1029/2005GL025347.

- R. Wu, and X. Fu, 2000: Pacific East-Asia teleconnection: How does ENSO affect East Asian climate? J. Climate, 13, $1517-1536$.

- - - , and T. Li, 2003: Atmosphere -warm ocean interaction and its impact on Asian-Australian monsoon variation. J. Climate, 16, 1195-1211.

—, I.-S. Kang, and J.-Y. Lee, 2004: Ensemble simulations of Asian-Australian monsoon variability by 11 AGCMs. J. Climate, 17, 803-818.

—, Q. Ding, X. Fu, I. S. Kang, K. Jin, J. Shukla, and F. DoblasReyes, 2005: Fundamental challenge in simulation and prediction of summer monsoon rainfall. Geophys. Res. Lett., 32, L15711, doi:10.1029/2005GL022734.

Webster, P., V. Magaña, T. Palmer, J. Shukla, R. Tomas, M. Yanai, and T. Yasunari, 1998: Monsoons: Processes, predictability, and the prospects for prediction. J. Geophys. Res., 103, 14 451-14 510.

Wentz, F., and R. Spencer, 1998: SSM/I rain retrievals within a unified all-weather ocean algorithm. J. Atmos. Sci., 55, 16131627.

Willmott, C., and K. Matsuura, 2001: Terrestrial air temperature and precipitation: Monthly and annual time series (1950 1999). [Available online at http://climate.geog.udel.edu/ $\sim$ climate/html_pages/README.ghcn_ts2.html.]

Wu, R., and B. Kirtman, 2007: Regimes of seasonal air-sea interaction and implications for performance of forced simulations. Climate Dyn., 29, 393-410.

and K. Pegion, 2006: Local air-sea relationship in observations and model simulations. J. Climate, 19, 49144932.

Xie, P., and P. Arkin, 1996: Analyses of global monthly precipitation using gauge observations, satellite estimates, and numerical model predictions. J. Climate, 9, 840-858. 
Xin, X., R. Yu, T. Zhou, and B. Wang, 2006: Drought in late spring of South China in recent decades. J. Climate, 19, 31973206.

Yang, J., Q. Liu, S. Xie, Z. Liu, and L. Wu, 2006: Impact of the Indian Ocean SST basin mode on the Asian summe monsoon. Geophys. Res. Lett., 34, L02708, doi:10.1029/ 2006GL028571.

Yang, S., and K. Lau, 2006: Interannual variability of the Asian monsoon. The Asian Monsoon, B. Wang, Ed., SpringerPraxis, 259-293.

Yu, R., and T. Zhou, 2007: Seasonality and three-dimensional structure of the interdecadal change in the East Asian monsoon. J. Climate, 20, 5344-5355.
—, B. Wang, and T. Zhou, 2004: Tropospheric cooling and summer monsoon weakening trend over East Asia. Geophys. Res. Lett., 31, L22212, doi:10.1029/2004GL021270.

Zhang, G., and H. Wang, 2006: Toward mitigating the double ITCZ problem in NCAR CCSM3. Geophys. Res. Lett., 33, L06709, doi:10.1029/2005GL025229.

Zhou, T., and R. Yu, 2004: Sea-surface temperature induced variability of the Southern Annular Mode in an atmospheric general circulation model. Geophys. Res. Lett., 31, L24206, doi:10.1029/2004GL021473.

, and - 2006: Twentieth-century surface air temperature over China and the globe simulated by coupled climate models. J. Climate, 19, 5843-5858. 